Boletín de la Sociedad Geológica Mexicana

Volumen 61, NúM. 3, 2009, P. 375-402

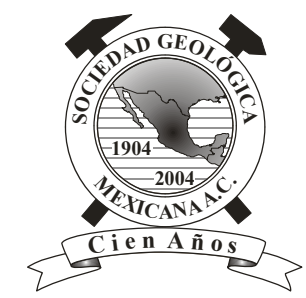

\title{
Gneises bandeados paleoproterozoicos ( 1.76-1.73 Ga) de la Zona Canteras-Puerto Peñasco: Una nueva ocurrencia de rocas de basamento tipo Yavapai en el NW de Sonora, México
}

\author{
Harim E. Arvizu ${ }^{1,2 *}$, Alexander Iriondo ${ }^{2 * *}$, Aldo Izaguirre ${ }^{2}$, Gabriel Chávez-Cabello ${ }^{1}$, \\ George D. Kamenov ${ }^{3}$, David A. Foster ${ }^{3}$, Rufino Lozano-Santa Cruz y \\ Gabriela Solís-Pichardo ${ }^{4}$ \\ ${ }^{1}$ Facultad de Ciencias de la Tierra, Universidad Autónoma de Nuevo León \\ Apartado postal 104, Kilómetro 8, Carretera Linares-Cerro Prieto, Linares, N.L., 67700, México. \\ ${ }^{2}$ Centro de Geociencias, Universidad Nacional Autónoma de México \\ Campus Juriquilla, Apartado Postal 1-742, Querétaro, Qro., 76230, México. \\ ${ }^{3}$ Department of Geological Sciences, University of Florida \\ Gainesville, Florida, 32611, USA. \\ ${ }^{4}$ Instituto de Geología, Universidad Nacional Autónoma de México \\ Ciudad Universitaria, México, D.F., 04510, México. \\ *harimarvizu@geociencias.unam.mx \\ **iriondo@geociencias.unam.mx
}

\section{Resumen}

La Zona Canteras-Puerto Peñasco, conocida anteriormente como Seven Hills, está localizada aproximadamente a $20 \mathrm{~km}$ al ENE de Puerto Peñasco en el NW de Sonora, México. El basamento cristalino presente en esta área es clave para definir las provincias proterozoicas del SW de Laurencia y tiene importantes implicaciones para la tectónica Fanerozoica y para la formación del margen continental activo de Norteamérica. Nuevas edades U-Pb en zircones (LA-MC-ICPMS) de dos gneises bandeados de la Zona CanterasPuerto Peñasco proporcionan edades ${ }^{207} \mathrm{~Pb} /{ }^{206} \mathrm{~Pb}$ de $1764 \pm 3$ Ma y $1725 \pm 3 \mathrm{Ma}$. Los zircones de ambas muestras están bien preservados y presentan una homogeneidad en composición y edad en cada caso sugiriendo que estas rocas son ortogneises paleoproterozoicos. Estas edades de cristalización combinadas con geoquímica de elementos mayores y traza en roca total y determinaciones isotópicas $\mathrm{Sm}-\mathrm{Nd}$ en roca total y Lu-Hf en zircones sugieren que los gneises bandeados tienen afinidad con rocas de la provincia Yavapai como las definidas en el área de Quitovac, aproximadamente a $45 \mathrm{~km}$ al este del área de estudio y en la región de Gunnison-Salida en Colorado, EUA. Ambas muestras caen en el campo de ambiente de arco volcánico de formación de granitos (diagrama de discriminación Y vs $\mathrm{Nb}$ ) y tienen valores de épsilon Hf inicial entre +1.85 y +5.05 con correspondientes edades modelo Hf ( $\left.\mathrm{T}_{\mathrm{DM}}\right)$ en un paso ("singlestage model ages") de 1.98-2.07 Ga y edades modelo $\mathrm{Hf}\left(\mathrm{T}_{\mathrm{DM}}{ }^{\mathrm{C}}\right)$ en dos pasos ("two-stage model ages") de 2.07-2.50 Ga. Análisis isotópicos de $\mathrm{Sm}-\mathrm{Nd}$ en roca total de tres gneises paleoproterozoicos presentan valores iniciales de épsilon $\mathrm{Nd}$ entre $+1.86 \mathrm{y}-0.57 \mathrm{y}$ edades modelo $\mathrm{Nd}\left(\mathrm{T}_{\mathrm{DM}}\right)$ de 1.91-2.02 Ga.

Concluimos que los protolitos ígneos de estos gneises de la Zona Canteras-Puerto Peñasco pudieron haber sido formados por fuentes mantélicas con algún grado de contribución cortical, similar a las rocas de la provincia Yavapai en el SW de Norteamérica. Esto contrasta con la petrogénesis de las rocas típicas de la provincia Mojave, caracterizadas por una gran contaminación cortical (hasta valores de 30-40\% en Death Valley) e implicaría que de existir rocas tipo Mojave en el NW de Sonora, éstas deberían de encontrarse al oeste de la Zona Canteras-Puerto Peñasco.

Palabras clave: geocronología U-Pb en zircones, geoquímica, isótopos Sm-Nd y Lu-Hf, Zona Canteras-Puerto Peñasco, NW Sonora, México 
Abstract

The Zona Canteras-Puerto Peñasco area, previously known as Seven Hills, is located $20 \mathrm{~km}$ ENE of the town of Puerto Peñasco in NW Sonora, Mexico. Crystalline basement in this area is key to defining Proterozoic provinces of SW Laurentia and has important implications for Phanerozoic tectonics and formation of the active continental margin of North America. New U-Pb zircon ages (LAMC-ICPMS) of two banded gneisses in this area yield ${ }^{207} \mathrm{~Pb} /{ }^{206} \mathrm{~Pb}$ ages at $1764 \pm 3 \mathrm{Ma}$ and $1725 \pm 3 \mathrm{Ma}$. Zircons from both samples are well-behaved in the U-Pb systematics and present age and compositional homogeneity, suggesting that these rocks are Paleoproterozoic orthogneisses. These crystallization ages combined with whole rock major-and trace-element geochemistry and Sm-Nd in whole rock and Lu-Hf isotopic determinations on zircons by laser ablation suggest that the banded gneisses have affinities with rocks of the Yavapai province as defined in the Quitovac area $\sim 5 \mathrm{~km}$ to the east and in the region of Gunnison-Salida, Colorado, USA. Both samples plot in the volcanic arc environment of granite formation ( $Y v s \mathrm{Nb}$ discrimination diagram) and have epsilon Hf (initial) values between +1.85 and +5.05 with corresponding single-stage Hf model ages $\left(T_{D M}\right)$ at 1.98-2.07 Ga and two-stage Hf model ages $\left(T_{D M}{ }^{C}\right)$ at 2.07$2.50 \mathrm{Ga}$. Sm-Nd whole rock isotopic analyses from three Paleoproterozoic gneisses have epsilon Nd (initial) values between +1.86 and -0.57 with corresponding $N d$ model ages $\left(T_{D M}\right)$ at 1.91-2.02 Ga.

The magmatic protoliths of these gneisses could have been formed mostly from mantle sources with some degree of crustal contribution, which is similar to rocks from the Yavapai province in SW North America. This petrogenesis contrasts with typical Mojave-province rocks that are characterized by significantly greater crustal contamination (as much as 30-40\% in Death Valley). If these Mojave province rocks exist in NW Sonora they must be located to the west of the Zona Canteras-Puerto Peñasco area.

Key words: U-Pb zircon geochronology, geochemistry, Sm-Nd and Lu-Hf isotopics, Zona Canteras-Puerto Peñasco, NW Sonora, México

\section{Introducción}

En las últimas décadas, el SW de los Estados Unidos de América (EUA) ha sido objeto de numerosos estudios del basamento que han permitido caracterizar y proponer una división, más o menos clara, de las rocas paleoproterozoicas en el margen continental del SW de Laurencia en tres diferentes provincias: Mojave, Yavapai y Mazatzal, así como los límites que las separan (Figura 1, Tabla 1; p. ej., Iriondo et al., 2004; Iriondo y Premo, 2009). Los primeros estudios sobre basamento paleoproterozoico en México, realizados en el NW de Sonora, proponían la extensión de estas provincias hacia México basándose en información geológica restringida sólo a descripciones estratigráficas y litológicas, existiendo pocas determinaciones geocronológicas (Damon et al., 1961, 1962; Anderson y Silver, 2005).

No fue hasta que estudios geológicos multidisciplinarios, en regiones como Quitovac (Iriondo et al., 2004) y Cabeza Prieta-Pinacate (Nourse et al., 2005, Figura 2), permitieron proponer tentativamente la existencia de por lo menos dos estilos bien diferenciados de rocas paleoproterozoicas en Sonora similares a las de las provincias Yavapai y Mazatzal del SW de Norteamérica (Figura 1). Trabajos más recientes de caracterización temporal, geoquímica e isotópica del basamento paleoproterozoico del NW de Sonora, realizados en Sierra Prieta y Cerro Prieto-Carina (Izaguirre-Pompa e Iriondo, 2007; Izaguirre et al., 2008) y Cerros San Luisito (Gutiérrez-Coronado et al., 2008, Figura 2A), también sugieren la existencia de basamento tipo Yavapai en esta región. Por otro lado, otros estudios en la región también han propuesto la existencia de basamento paleoproterozoico tipo Mojave (Castiñeiras et al., 2004a, b; Dórame-Navarro et al., 2004; Farmer et al., 2005; Soto-Verdugo, 2006).
Una nueva ocurrencia de rocas paleoproterozoicas de la Zona Canteras-Puerto Peñasco en el NW de Sonora, que se presenta en este estudio, sugiere mediante estudios de geocronología $\mathrm{U}-\mathrm{Pb}$ en zircones, geoquímica de elementos mayores y traza, isótopos $\mathrm{Sm}-\mathrm{Nd}$ en roca total y estudios de Lu-Hf en zircones, que el basamento cristalino en esta área presenta similitudes con rocas asociadas a la provincia Yavapai. El basamento paleoproterozoico presente en esta zona es muy importante para definir la delimitación y distribución de las provincias paleoproterozoicas del SW de Laurencia en su parte mexicana, ya que la Zona Canteras-Puerto Peñasco se encuentra en la porción más occidental de la franja del Yavapai mexicano en el NW de Sonora (Figuras 1 y 2).

En definitiva, esta nueva localidad de provincias paleoproterozoicas en el NW de México permitirá tener un mejor entendimiento geológico del margen SW de Laurencia que pudiera ser empleado para evaluar las diferentes reconstrucciones existentes del supercontinente Rodinia (Li et al., 2008).

\section{El basamento paleoproterozoico del SW de Laurencia en México}

Antes de iniciar este apartado nos parece pertinente presentar una visión general sobre el significado geológico de las provincias corticales paleoproterozoicas del margen SW de Laurencia (SW de EUA) que permita al lector comprender la naturaleza del tema. Las provincias corticales paleoproterozoicas del SW de Norteamérica son tres: Mojave, Yavapai y Mazatzal, las cuales están separadas por fronteras o límites geológicos (p. ej. fronteras de provincias de $\mathrm{Nd}$, frontera geoquímica Mojave-Yavapai, Figura 1). Cada provincia posee características geológicas especiales (p. ej. geoquímicas e isotópicas) que difieren 

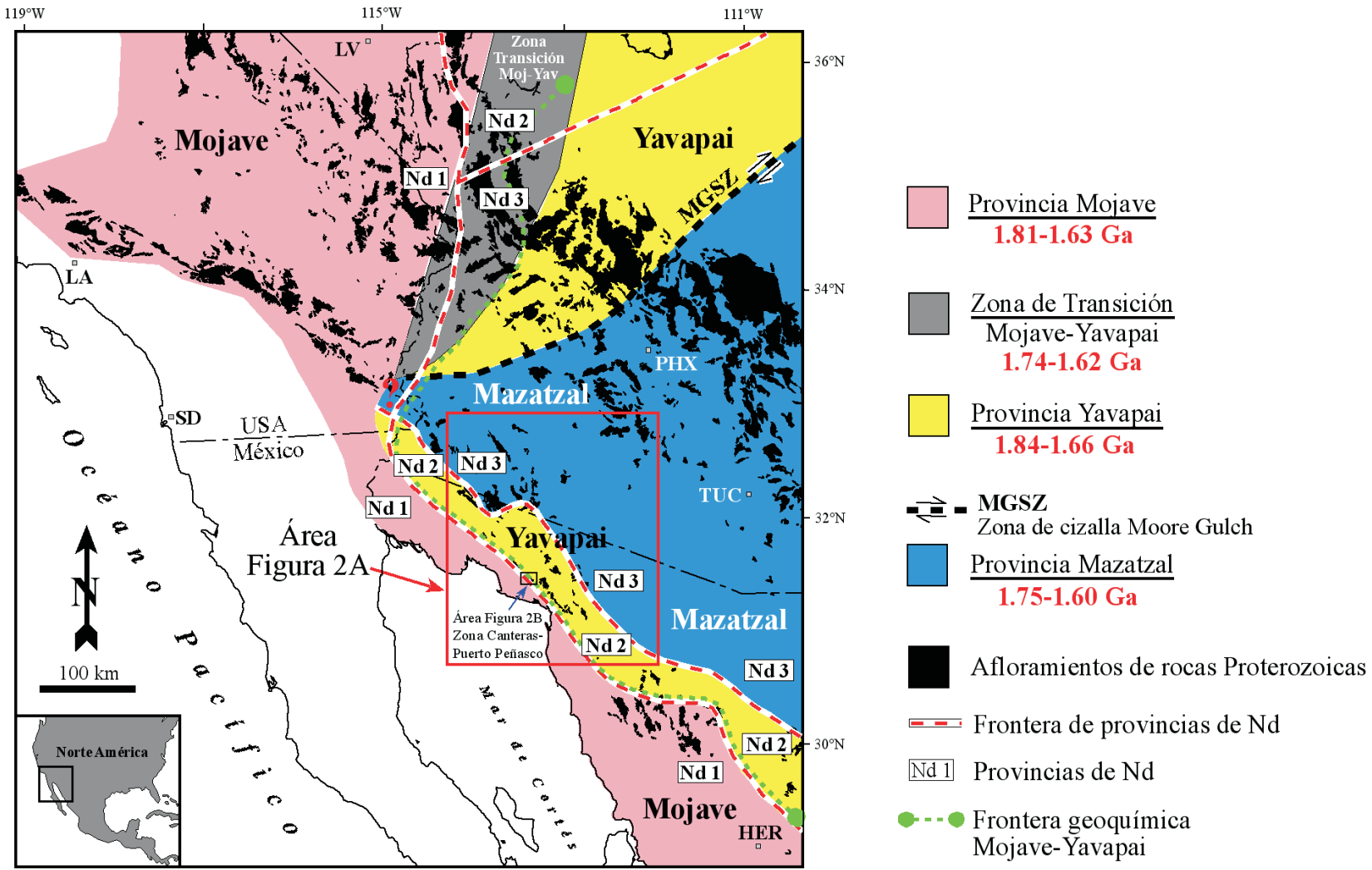

Figura 1. Distribución tentativa de las provincias paleoproterozoicas Mojave, Yavapai y Mazatzal en el SW de Laurencia incluyendo los afloramientos del NW de México (Iriondo y Premo, 2009). El rango de edades de cristalización para cada una de las provincias está basado en la recopilación de edades de Iriondo et al. (2004). También se presenta, de forma tentativa, la extensión de la traza de fronteras de $\mathrm{Nd}$ y de las series geoquímicas al internarse hacia México (Iriondo y Premo, 2009). Las abreviaciones son LA: Los Ángeles, SD: San Diego, LV: Las Vegas, PHX: Phoenix, TUC: Tucson, HER: Hermosillo.

entre ellas. Cada provincia posee características geológicas especiales (p. ej. geoquímicas e isotópicas) que difieren entre ellas. Algo notable es que las provincias y sus fronteras geológicas propuestas se han definido, no por sus edades, sino por sus características estructurales, isotópicas y geoquímicas, ya que existe un traslape de edades entre las mismas (Iriondo et al., 2004). Por ejemplo, Bennet y DePaolo (1987) dividieron el basamento paleoproterozoico del SW de los Estados Unidos en tres diferentes provincias separadas por fronteras o límites utilizando valores isotópicos de Nd (Figura 1). La provincia de Nd 1 correspondiente a rocas de corteza proterozoica de la provincia Mojave tiene las edades modelo de $\mathrm{Nd}\left(\mathrm{T}_{\mathrm{DM}}\right)$ más antiguas, entre 2.3-2.0 $\mathrm{Ga}$, y los valores de épsilon $\mathrm{Nd}$ iniciales más negativos, entre $-3 \mathrm{y}+1$. La provincia de $\mathrm{Nd} 2$ representa una corteza proterozoica de basamento Mojave y Yavapai con edades modelo de $\mathrm{Nd}\left(\mathrm{T}_{\mathrm{DM}}\right)=2.0-1.8 \mathrm{Ga}$ y valores de épsilon $\mathrm{Nd}$ iniciales entre +0.8 y +4.7 . Por su parte, la provincia de $\mathrm{Nd} 3$ corresponde a rocas de basamento de las provincias Yavapai y Mazatzal con las edades modelo de $\mathrm{Nd}\left(\mathrm{T}_{\mathrm{DM}}\right)$ más jóvenes, entre 1.8-1.7 Ga, y con los valores de épsilon $\mathrm{Nd}$ iniciales más positivos $(+5)$ de todas las provincias. Anderson et al. (1993) y Bender (1994) proponen otro límite geológico definido con base en estudios geoquímicos que sugieren una frontera composicional entre las provincias Mojave y Yavapai.

Para mayor información se refiere al lector a la Tabla 1 en donde se encuentran listadas algunas de las características más importantes para cada una de estas provincias y para información detallada sobre el tema referimos a Iriondo y Premo (2009).

Los primeros estudios geocronológicos sobre el basamento paleoproterozoico del NW de México fueron realizados en Sonora por Damon et al. (1961, 1962) utilizando técnicas de $\mathrm{K}-\mathrm{Ar}$ y $\mathrm{Rb}-\mathrm{Sr}$, proponiendo que el basamento paleoproterozoico del SW de los EUA podría extenderse hacia Sonora.

Trabajo de campo subsecuente y geocronología de $\mathrm{U}-\mathrm{Pb}$ en zircones en la región, realizados en los 70's y posteriormente detallados por Anderson y Silver (2005), identificaron rocas de basamento cristalino proterozoico con edades desde el Paleoproterozoico $(\sim 1.8-1.6 \mathrm{Ga})$ hasta el Mesoproterozoico ( 1.4 y 1.1 Ga). Estos estudios geocronológicos en el NW de Sonora sirvieron de base para plantear como hipótesis la existencia de la megacizalla Mojave-Sonora, (MSM) que sugiere la yuxtaposición de 


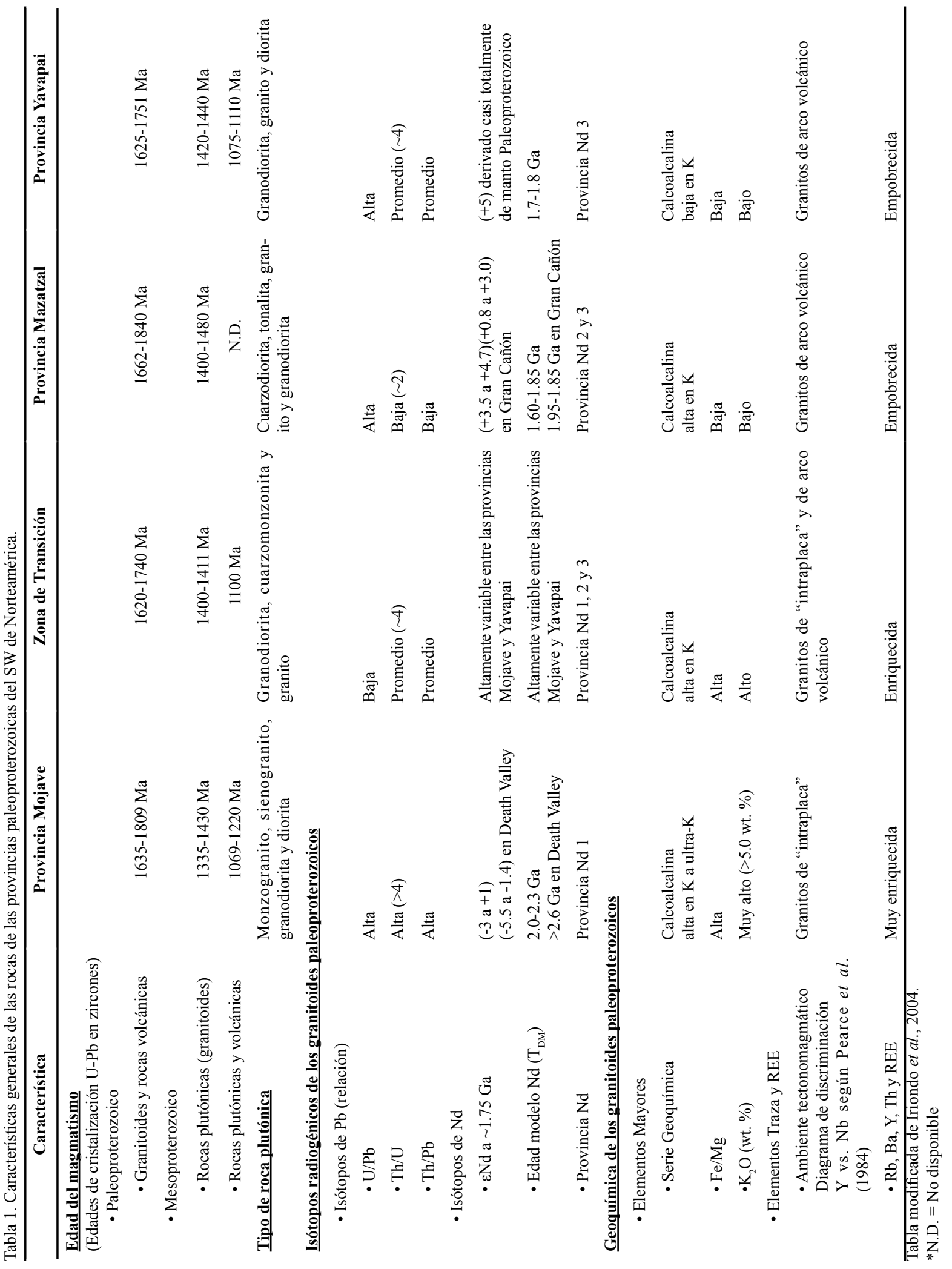


dos basamentos cristalinos paleoproterozoicos o bloques de edad diferente: bloque Caborca y bloque "Norte América" (Silver y Anderson, 1974, 1983; Anderson y Silver, 1978, 1979; Anderson y Schmidt, 1983).

Iriondo et al. (2004) distinguieron, basándose en estudios geocronológicos, geoquímicos e isotópicos, dos bloques paleoproterozoicos en la región de Quitovac en el NW de Sonora (Figura 2A). El primero, el bloque Caborca con edades U-Pb en zircones entre 1693-1777 Ma, presenta valores de épsilon $\mathrm{Nd}$ iniciales entre $+0.6 \mathrm{y}+2.6 \mathrm{y}$ edades modelo $\mathrm{Nd}_{\mathrm{DM}}$ entre 1.88-2.07 Ga, correlacionándose éste bloque con rocas de la provincia Yavapai. El segundo es el bloque "Norte América", que se correlaciona con la provincia Mazatzal y tiene edades U-Pb entre 1656-1714 $\mathrm{Ma}$, valores de épsilon $\mathrm{Nd}$ iniciales de $+3.4 \mathrm{a}+3.9$ y correspondientes edades modelo $\mathrm{Nd}_{\mathrm{DM}}$ entre 1.74 y $1.80 \mathrm{Ga}$.

Nourse et al. (2005) en la región de Cabeza PrietaPinacate (Figura 2A), al igual que Iriondo et al. (2004) en la región de Quitovac, definieron dos tipos de basamento paleoproterozoico. En general, las rocas de esta región tienen edades $\mathrm{U}-\mathrm{Pb}$ en zircones entre 1696 y $1725 \mathrm{Ma}$ con valores iniciales de épsilon $\mathrm{Nd}$ entre $+2 \mathrm{y}+4$ y con edades modelo $\mathrm{Nd} \mathrm{T}_{\mathrm{DM}}$ entre 1.65 y $1.80 \mathrm{Ga}$. De acuerdo con las edades y firmas isotópicas de $\mathrm{Nd}$, las rocas más orientales en esa región se relacionan con las de la provincia Mazatzal, mientras que las más occidentales lo están con las de la provincia Yavapai de Arizona, contrastando notablemente con las del basamento tipo Mojave (épsilon $\mathrm{Nd}=-5.5 \mathrm{a}-1.4$ y edades modelo $\mathrm{Nd} \mathrm{T}_{\mathrm{DM}}=2.0$ a $2.6 \mathrm{Ga}$ ).

Trabajos más recientes de caracterización temporal, geoquímica e isotópica del basamento paleoproterozoico del NW de Sonora incluyen los realizados en Sierra Prieta y Cerro Prieto-Carina (Izaguirre-Pompa e Iriondo, 2007; Izaguirre et al., 2008) y los realizados en Cerros San Luisito (Gutiérrez-Coronado et al., 2008, Figura 2A) sugiriendo la existencia de basamento tipo Yavapai para estas zonas. En Cerros San Luisito, $30 \mathrm{~km}$ al SE de Quitovac, las rocas gnéisicas tienen edades entre 1676 y 1712 Ma y muestran valores iniciales de épsilon $\mathrm{Nd}$ de $+1.13 \mathrm{a}+2.87$ con correspondientes edades modelo $\mathrm{Nd}_{\mathrm{DM}}$ entre 1.76-1.91 Ga, mientras que para la región de Cerro Prieto-Carina las rocas alcanzan edades U-Pb en zircones entre 1682 y 1687 Ma con valores de épsilon $\mathrm{Nd}$ entre $+0.52 \mathrm{y}+1.7 \mathrm{y}$ edades modelo $\mathrm{Nd} \mathrm{T}_{\text {DM }}$ entre 1.80 y $1.91 \mathrm{Ga}$.

Otros estudios más alejados de la Zona Canteras-Puerto Peñasco incluyen los del granito El Crestón, localizado en la región de Opodepe (centro de Sonora). Para este granito se ha reportado una edad U-Pb en zircones de $1730 \mathrm{Ma}$ y un valor inicial de épsilon $\mathrm{Nd}$ de +3.1 (Valenzuela-Navarro et al., 2003) considerándose como parte del bloque Caborca (basamento con características tipo Yavapai). Farmer et al. (2005) fecharon un intrusivo granítico en el Cerro El Rajón, al este del Rancho Bámuri, en $1699 \pm 2$ Ma y realizaron estudios isotópicos $\mathrm{Sm}-\mathrm{Nd}$ de esta unidad determinando valores de épsilon $\mathrm{Nd}$ de +0.17 y edades modelo $\mathrm{Nd} \mathrm{T}_{\mathrm{DM}}$ de $1.93 \mathrm{Ga}$ que nosotros definimos como un intrusivo asociado a un basamento tipo Yavapai. Amato et al. (2008) también reportan rocas proterozoicas similares a las de la provincia Yavapai en la región del Rancho La Lámina, cerca de Cucurpe, aproximadamente a $40 \mathrm{~km}$ al norte de la postulada megacizalla Mojave-Sonora en el norte-centro de Sonora. Los granitoides paleoproterozoicos en esta región tienen edades U-Pb en zircones de 1763, 1738 y $1737 \mathrm{Ma}$ con valores iniciales de épsilon $\mathrm{Nd}$ de $+0.5,+1.4 \mathrm{y}-4.3$, respectivamente.

Los trabajos llevados a cabo en la región del Rancho Bámuri, Cerros El Tecolote y La Tortuga, al S y SW de Caborca (Premo et al., 2003; Castiñeiras et al., 2004a, b, 2005; Dórame et al., 2004; Dórame-Navarro e Iriondo, 2005; Farmer et al., 2005) señalan que las rocas presentes en la región se correlacionan con las presentes en la provincia Mojave del SE de California y NW de Arizona (Figura 1). Las edades U-Pb de cristalización en zircones varían de 1765-1780 Ma, con valores iniciales de épsilon Nd entre -5.0 y +0.5 . Las rocas de basamento paleoproterozoico de la Sierrita Prieta, al W de Benjamín Hill, en el NW de Sonora, también presentan características similares a rocas de la provincia Mojave, proponiendo de igual manera la continuación de esta provincia hacia el NW de México (Soto-Verdugo, 2006). Estas rocas tienen edades U-Pb en zircones entre 1727 y $1733 \mathrm{Ma}$, edades un poco más jóvenes que las presentes en la región del Rancho Bámuri, y presentan valores iniciales de épsilon $\mathrm{Nd}$ entre -1.1 y -0.5 con correspondientes edades modelo $\mathrm{Nd} \mathrm{T}_{\mathrm{DM}}$ entre 2.0 y 2.1 Ga (Soto-Verdugo, 2006).

Todas estas contribuciones realizadas en la geología paleoproterozoica de Sonora permiten el avance del conocimiento geológico sobre el basamento en el NW de México y contribuyen a obtener una visión más clara sobre la distribución de las provincias paleoproterozoicas en el SW de Laurencia (Figura 1).

\section{Geología de la Zona Canteras-Puerto Peñasco}

La Zona Canteras-Puerto Peñasco, también conocida como Seven Hills (Anderson y Silver, 2005), está localizada aproximadamente a $20 \mathrm{~km}$ hacia el ENE de la ciudad de Puerto Peñasco, en el NW de Sonora (Figura 2). Seven Hills es un nombre informal que se utilizó para un conjunto de siete pequeños cerros alineados, mostrando un patrón de orientación aproximadamente de $\mathrm{S} 45^{\circ} \mathrm{E}$ (Figura 3A). El único trabajo reportado para esta zona es el realizado por Anderson y Silver (2005) en el cual identifican un conjunto de siete cerros, de los cuales reportan que cuatro están compuestos por rocas metamórficas, incluyendo gneises cuarzo-feldespáticos, paragneises, ortogneises y anfibolitas con edades $\mathrm{U}-\mathrm{Pb}$ paleoproterozoicas de $\sim 1.6-1.7$ Ga. El resto de los cerros están compuestos por rocas volcánicas, principalmente de composición riolítica-dacítica, cartografiadas como de edad miocénica (SGM, 2002).

En el presente estudio se identificó que la mayoría de los cerros están compuestos por gneises bandeados, clasificados 


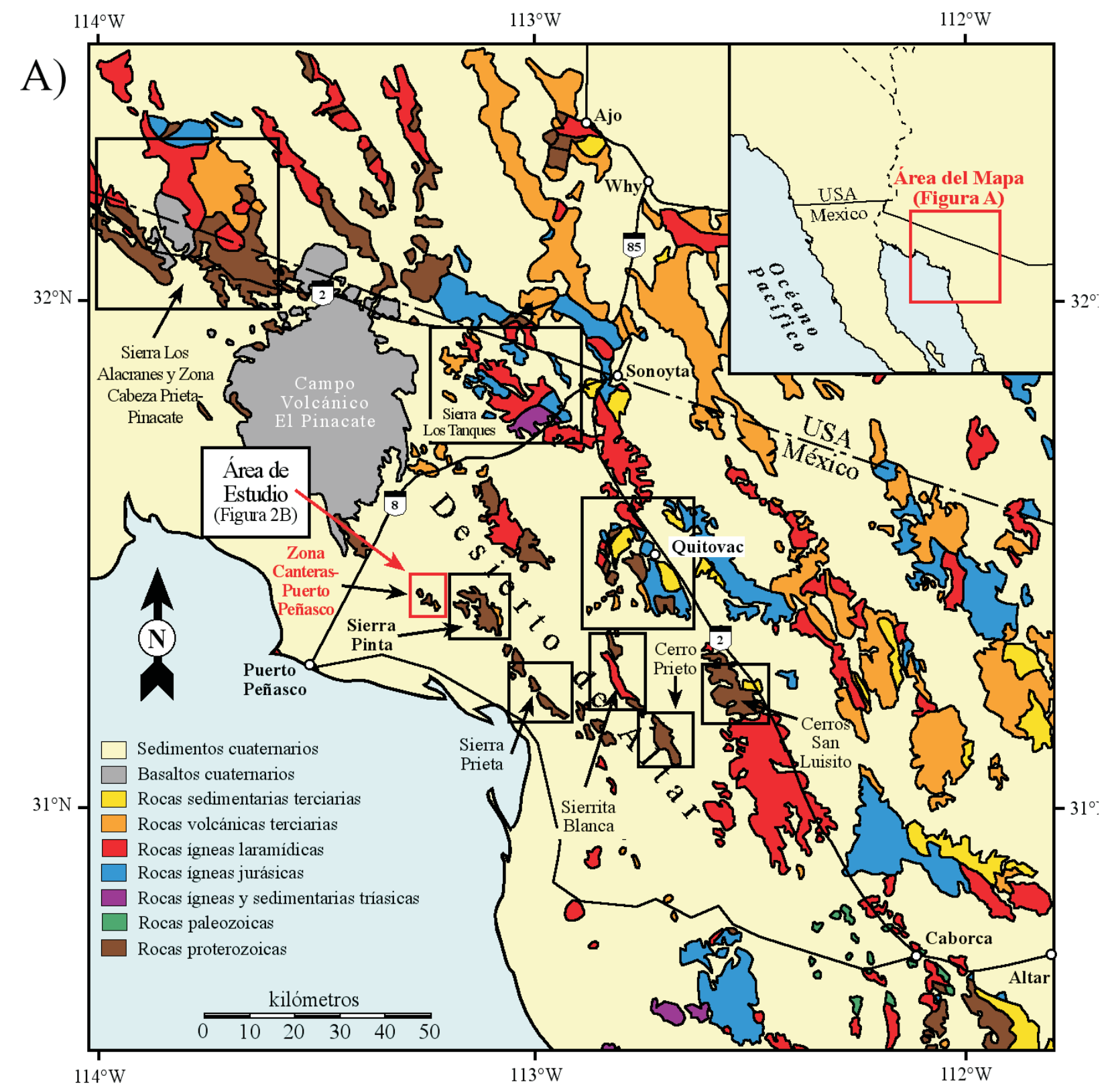

Figura 2. (A) Mapa litológico regional del NW de Sonora y SW de Arizona modificado de Iriondo et al. (2005). Los recuadros indican localidades mencionadas y discutidas en el texto.

petrográficamente como gneises cuarzo-feldespáticos de biotita y moscovita (Figuras 3B y C, Tabla 2). Los estudios de caracterización temporal, geoquímica e isotópica se desarrollaron sólo en dos muestras con este tipo de litología, ya que existía la posibilidad de que el protolito para estas rocas, de composición homogénea en toda el área, fuera ígneo, de acuerdo a la textura de la roca, lo cual es importante para determinar la edad de cristalización de la roca. Estas rocas constituidas por cuarzo, feldespato potásico, biotita y moscovita muestran una textura grano-lepidoblástica.

En algunos sectores los gneises se encuentran muy foliados definidos por la orientación de biotita y por el bandeamiento que forman los minerales leucocráticos (Figura 3B). En el sector de escasa foliación la roca parece preservar su textura ígnea inicial mostrando una textura de aspecto granudo (Figura 3C).

En la Zona Canteras-Puerto Peñasco también se encontraron esquistos y anfibolitas, además de paragneises y ortogneises como lo propusieron Anderson y Silver (2005, Figura 3D). Los gneises bandeados muestran un patrón de foliación generalmente homogéneo con rumbos entre $30^{\circ}$ y $60^{\circ} \mathrm{NW}$ con echados variables, predominando valores 
entre $40-70^{\circ}$ hacia el SW. También se puede observar otra pequeña familia con rumbos entre $30^{\circ}$ y $45^{\circ} \mathrm{NE}$ y echados hacia el NW (Figura 2B).

\section{Métodos analíticos}

\subsection{Muestreo, trituración y pulverización}

Con base en el estudio cartográfico realizado para reconocer las diferentes unidades geológicas se realizó un muestreo de las rocas representativas de la Zona CanterasPuerto Peñasco para llevar a cabo estudios geocronológicos, geoquímicos e isotópicos. Todas las muestras se procesaron para cada estudio específico en los respectivos laboratorios del Centro de Geociencias (CGEO), UNAM, Campus Juriquilla, Querétaro (Taller de Molienda, Laboratorio de Separación Mineral, etc.). Los procedimientos de muestreo, trituración, pulverizado de muestras, separación de zircones y las técnicas analíticas empleadas se encuentran descritas de forma más detallada en Arvizu-Gutiérrez (2008).

\subsection{Geocronología U-Pb en zircones}

Los análisis isotópicos de $\mathrm{U}-\mathrm{Pb}$ en zircones fueron realizados en el Departamento de Ciencias Geológicas de la Universidad de Florida en Gainesville, EUA, utilizando un espectrómetro de masas de tipo multicolector con plasma de acoplamiento inductivo marca Nu Plasma (Multi-collector Inductively Coupled Plasma Mass Spectrometry, MC-ICP$\mathrm{MS}$ ), equipado con 3 contadores de iones y 12 detectores Faraday. El MC-ICP-MS está equipado especialmente con diseño de bloque colector para adquisición simultánea de señales de ${ }^{204} \mathrm{~Pb}\left({ }^{204} \mathrm{Hg}\right),{ }^{206} \mathrm{~Pb}$ y ${ }^{207} \mathrm{~Pb}$ en 3 detectores contadores de iones y señales de ${ }^{235} \mathrm{U}$ y ${ }^{238} \mathrm{U}$ en los detectores Faraday. Esta disposición de componentes está detallada en Simonetti et al. (2005). Los granos de zircones montados en la probeta de resina sufrieron ablación en una atmósfera de He usando un láser ultravioleta New Wave de $213 \mathrm{~nm}$. La muestra vaporizada fue evacuada de la celda de ablación en un flujo de He y después mezclada con gas Ar (flujos de gas optimizados diariamente) para transportarla al espectrómetro de masas. Las mediciones de blancos analíticos ("background") fueron hechas antes de cada análisis con el fin de sustraer este componente, incluyendo ${ }^{204} \mathrm{Hg}$, de los análisis de zircón. La ablación se llevó a cabo por alrededor de 30 segundos con el fin de minimizar la profundidad del hoyo de ablación y, de la misma manera, el fraccionamiento elemental. La mayoría de los análisis U-Pb se llevaron a cabo con un haz de $\sim 30-40 \mu \mathrm{m}$ de diámetro creando un hoyo de $\sim 40-50 \mu \mathrm{m}$ de profundidad.

Los datos isotópicos fueron adquiridos utilizando el software analítico Nu-Instruments con resolución temporal, permitiendo que las relaciones isotópicas sean calculadas de los datos adquiridos en un intervalo de tiempo específico. La calibración de los datos y correcciones por deriva instrumental ("drift") fueron basadas en los estándares de zircón
R33 obtenido de una monzodiorita de edad $\sim 419 \mathrm{Ma}$ (Black et al., 2004) y el FC-1 obtenido del Gabro Duluth de edad $\sim 1.1 \mathrm{Ga}$ (Paces y Miller, 1993; Black et al., 2003). Los datos generados de los análisis isotópicos fueron procesados con un programa macro ("in house") de Excel; sin embargo, las edades y grados de concordancia fueron calculados y graficados usando el programa Isoplot 3.0 (Ludwig, 2003). Los valores U-Pb adquiridos en los análisis fueron normalizados mediante la relación ${ }^{206} \mathrm{~Pb} /{ }^{238} \mathrm{U}=0.1859$ del estándar de zircón FC-1 de edad de 1099 Ma (Paces y Miller, 1993). Las edades ${ }^{207} \mathrm{~Pb} /{ }^{206} \mathrm{~Pb}$ fueron corregidas por $\mathrm{Pb}$ común asumiendo composiciones de ${ }^{206} \mathrm{~Pb} / 204 \mathrm{~Pb}=$ $18.824 \mathrm{y}^{207} \mathrm{~Pb} /{ }^{204} \mathrm{~Pb}=15.671$ (Cumming y Richards, 1975) basadas en ${ }^{204} \mathrm{~Pb}$.

\subsection{Geoquímica de elementos mayores, traza y tierras raras}

Las muestras fueron analizadas para geoquímica de elementos mayores, trazas y tierras raras en el Laboratorio Universitario de Geoquímica Isotópica (LUGIS) del Instituto de Geología y en el Laboratorio Ultralimpio y de Espectrometría de Masas en el Centro de Geociencias (CGEO) de la UNAM.

Todas las muestras fueron analizadas por elementos mayores en el Laboratorio Universitario de Geoquímica Isotópica (LUGIS), UNAM, utilizando un aparato de Fluorescencia de Rayos X (FRX) marca Siemens modelo SRS-3000. Se realizaron análisis de muestras de roca pulverizada, de acuerdo a los procedimientos descritos por Lozano-Santa Cruz et al. (1995) y Verma et al. (1996).

Los datos de elementos traza se obtuvieron por espectrometría de masas de plasma inducido acoplado (Inductively Coupled Plasma Mass Spectrometry, ICP-MS). La mayoría de las muestras se analizaron en el CGEO utilizando un instrumento Thermo Series $\mathrm{X}^{\mathrm{II}}$.

Los métodos analíticos y procedimientos químicos empleados para el análisis de elementos mayores, traza y tierras raras, además de las condiciones de medición por Fluorescencia de Rayos X y Espectrometría de Masas se detallan en la página Web: Metodos analíticos empleados.

\subsection{Isótopos de $\mathrm{Sm}-\mathrm{Nd}$ en roca total}

Los análisis isotópicos Sm-Nd se realizaron en el Laboratorio Universitario de Geoquímica Isotópica (LUGIS) de la UNAM. Todas las determinaciones isotópicas de Sm-Nd se realizaron con un espectrómetro de masas Finnigan MAT262 equipado con nueve colectores Faraday y una fuente de doble filamento de Renio. Cuatro de los cinco colectores son regulables, independientes uno de otro, pudiéndose mover para poder recibir las distintas dispersiones de masa de los distintos elementos. En mediciones estáticas se registran las intensidades de hasta 7 masas simultáneamente. Todas las mediciones son llevadas a cabo con una corriente de $10 \mathrm{kV}$.

Para mayor información sobre la metodología utilizada y acerca de parámetros, como correcciones por fraccionamiento isotópico, correcciones de las mediciones por elementos, 


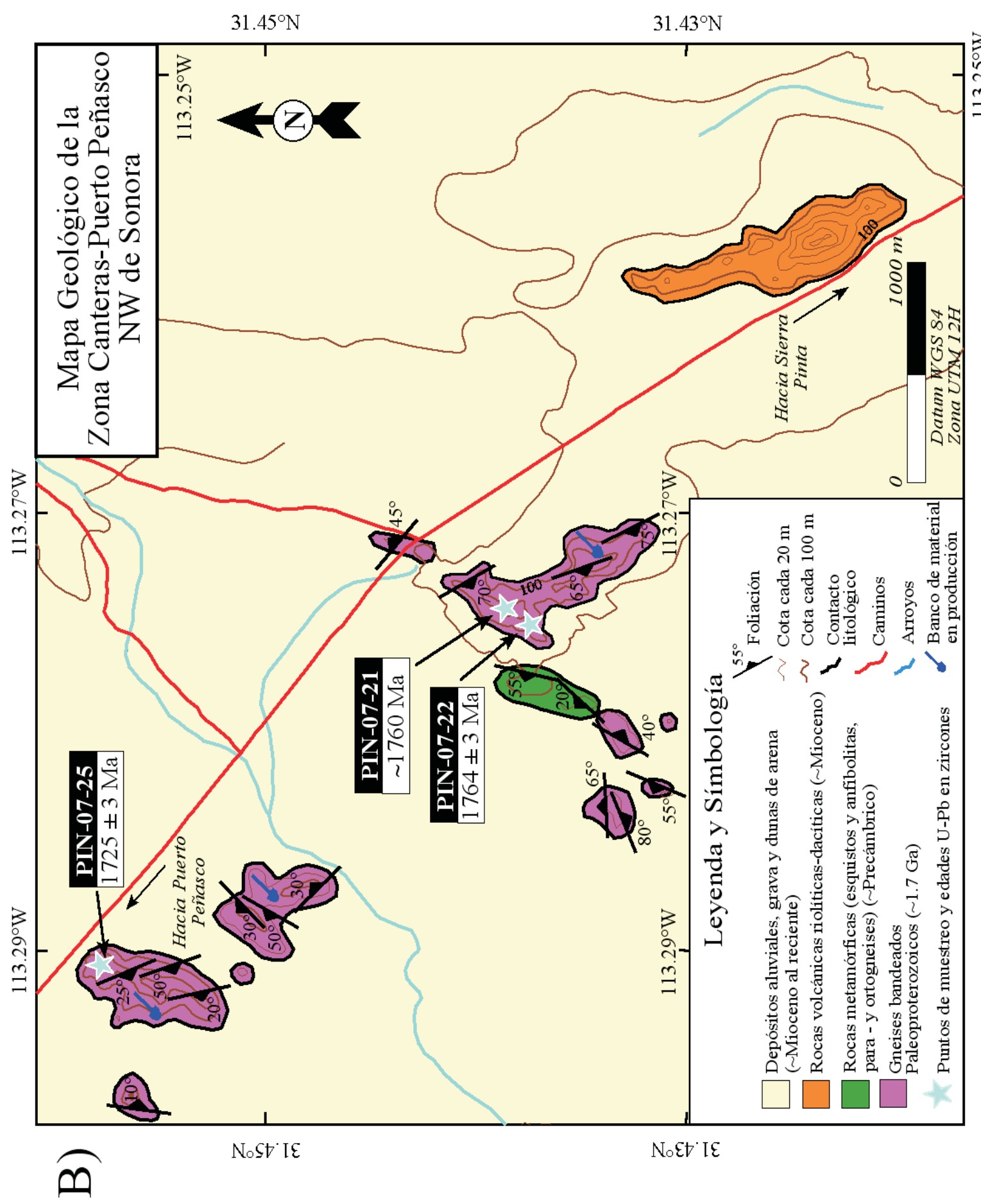




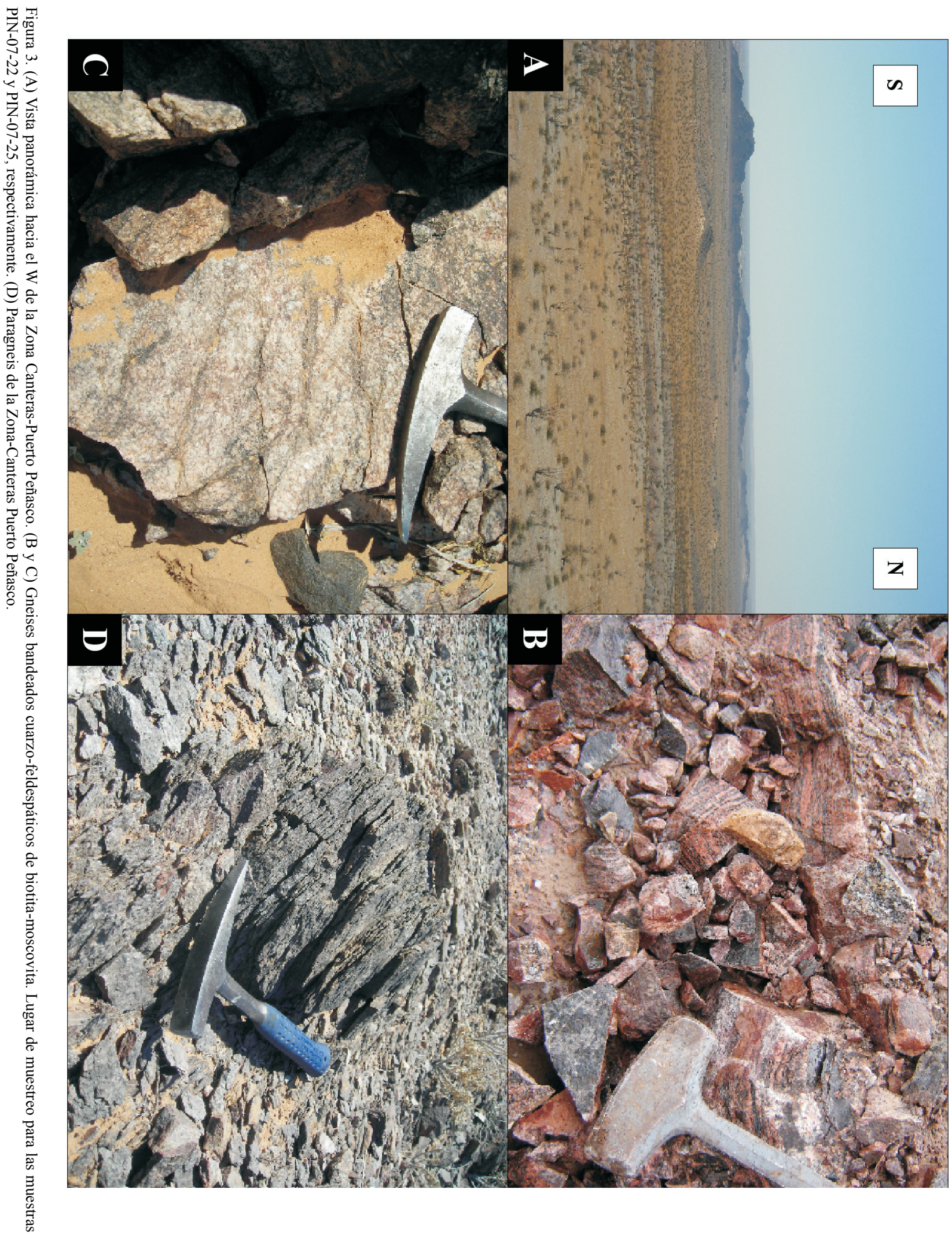



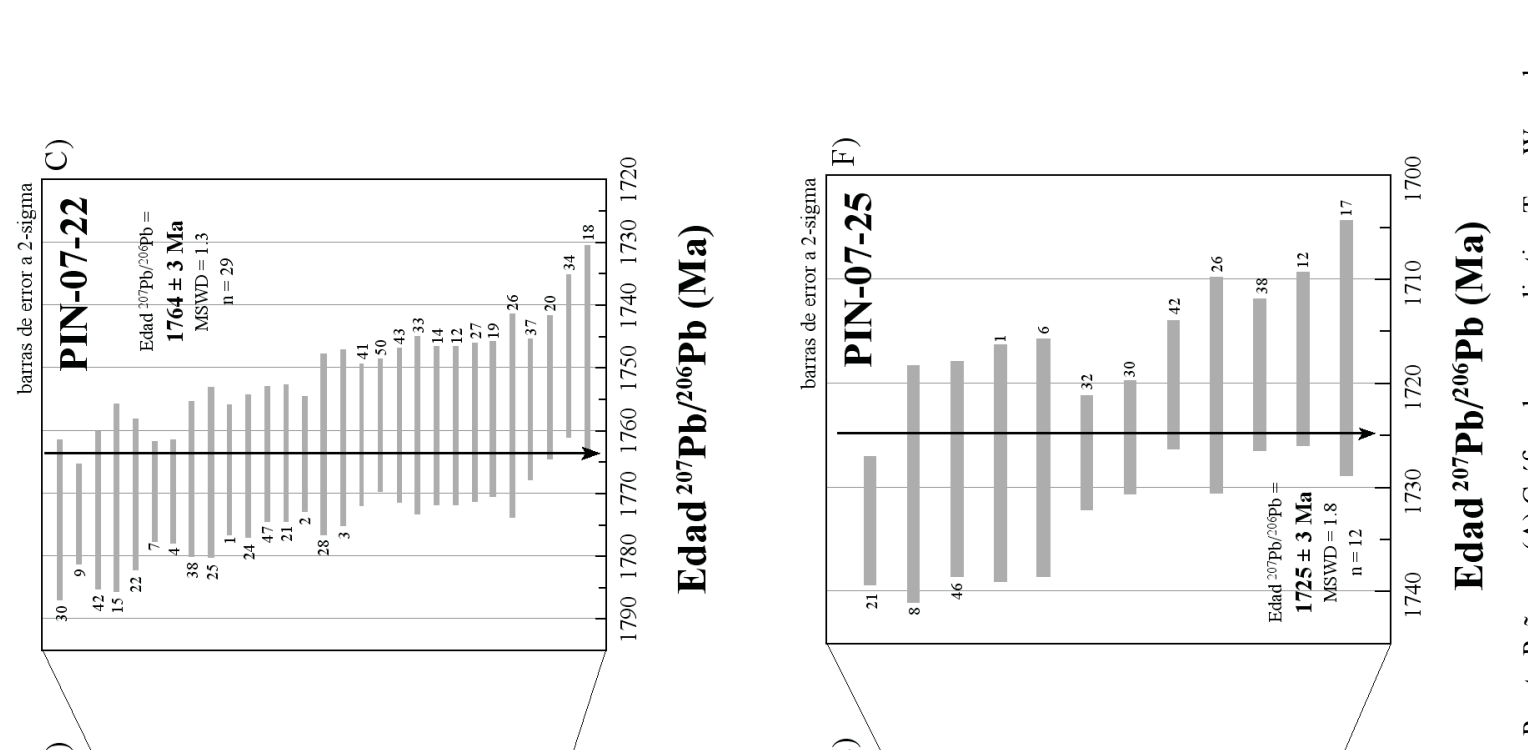

얄응 댕

政
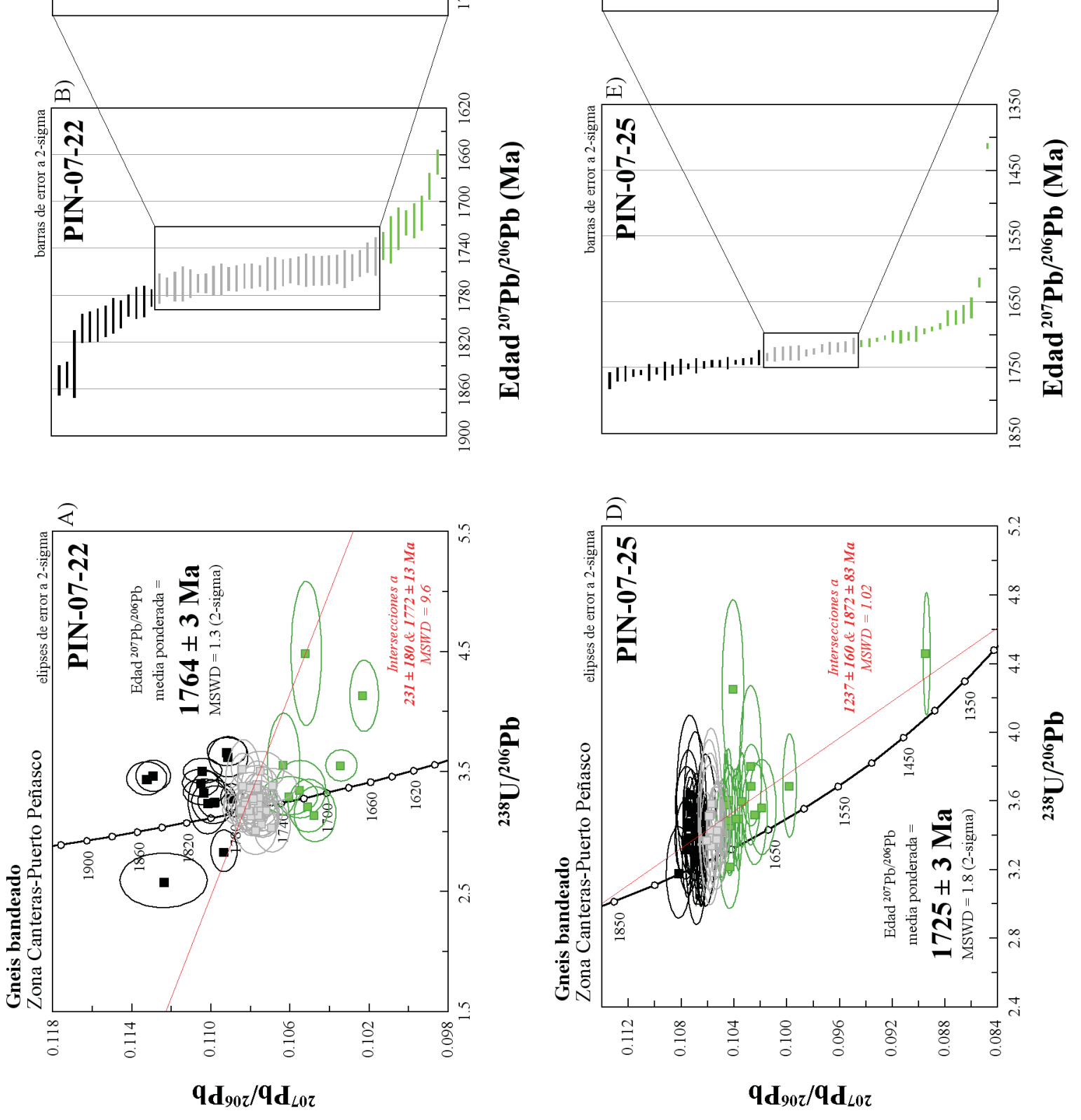

递

穿

孚

㻤

$\approx \%$

\&

可造

$\leq 00$

递包

远要

政

웅

造它

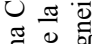

웅휴

젱

.

过高嵒

离言

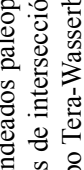

证

过

So

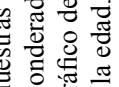

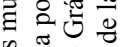

ส

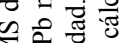

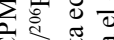

穴啳

$\sum_{1}$ 票

$\leq 8 \mathrm{~s}$

喽

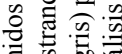

产

तิ

过客医言

츤 客흥

贺

定

षु 
Tabla 2. Localización de las muestras, clasificación, arreglos minerales y edades de las rocas estudiadas en la Zona Canteras-Puerto Peñasco, NW Sonora, México.

\begin{tabular}{|c|c|c|c|c|c|c|c|c|}
\hline Muestra & Localidad & $\begin{array}{c}\text { Latitud } \\
\left({ }^{\circ} \mathbf{N}\right)^{*}\end{array}$ & $\begin{array}{c}\text { Longitud } \\
\left({ }^{\circ} \mathrm{W}\right)\end{array}$ & Tipo de roca & $\begin{array}{l}\text { Minerales } \\
\text { Primarios } \\
\end{array}$ & $\begin{array}{c}\text { Minerales } \\
\text { Secundarios } \\
\end{array}$ & $\begin{array}{c}\text { Minerales } \\
\text { Accesorios } \\
\end{array}$ & Edad (Ma)** \\
\hline \multicolumn{9}{|c|}{ Gneises bandeados paleoproterozoicos } \\
\hline PIN-07-22 & $\begin{array}{l}\text { Zona Canteras - } \\
\text { Puerto Peñasco }\end{array}$ & $31^{\circ} 26^{\prime} 28^{\prime \prime}$ & $113^{\circ} 16^{\prime} 42^{\prime \prime}$ & $\begin{array}{l}\text { Gneis cuarzo- } \\
\text { feldespático } \\
\text { de biotita- } \\
\text { moscovita }\end{array}$ & $\mathrm{Qtz}+\mathrm{Kfs}+\mathrm{Bt}+\mathrm{Ms}$ & $\mathrm{Chl}$ & $\mathrm{Zrn}+\mathrm{Ap}$ & $1764 \pm 3 \mathrm{Ma}$ \\
\hline PIN-07-25 & $\begin{array}{l}\text { Zona Canteras - } \\
\text { Puerto Peñasco }\end{array}$ & $31^{\circ} 27^{\prime} 36^{\prime \prime}$ & $113^{\circ} 17^{\prime} 52^{\prime \prime}$ & $\begin{array}{l}\text { Gneis cuarzo- } \\
\text { feldespático } \\
\text { de biotita- } \\
\text { moscovita }\end{array}$ & $\mathrm{Qtz}+\mathrm{Kfs}+\mathrm{Bt}+\mathrm{Ms}$ & $\mathrm{Chl}+\mathrm{Ser}$ & $\mathrm{Zrn}+\mathrm{Ap}$ & $1725 \pm 3 \mathrm{Ma}$ \\
\hline
\end{tabular}

Abreviaturas: Qtz = Cuarzo, Kfs=Feldespato potásico, Bt=Biotita, Ms=Moscovita, Ser=Sericita, Chl=Clorita, Ap=Apatito, Zrn=Zircón.

**Edades U-Pb en zircones por técnica de ablación láser (LA-MC-ICPMS) reportadas a precisión 2 sigma.

LA-MC-ICPMS=Laser Ablation-MultiCollector-Inductively Coupled Plasma Mass Spectrometry: Ablación láser acoplado a espectrómetro de masas de tipo multicolector con plasma de acoplamiento inductivo.

*Datum WGS84.
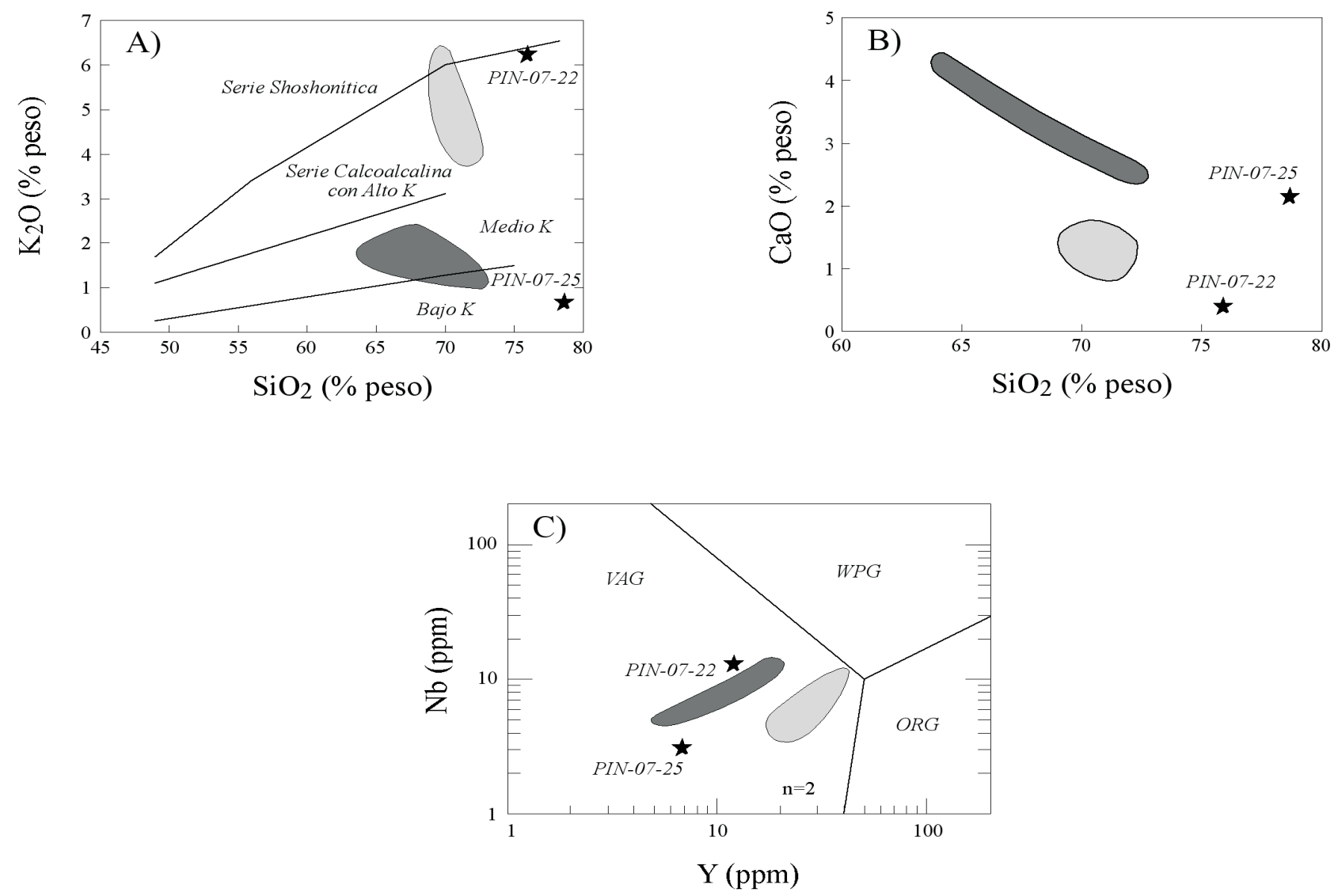

Figura 5. Diagramas discriminativos de la geoquímica de elementos mayores y traza de rocas proterozoicas de la Zona Canteras-Puerto Peñasco y Quitovac. Las estrellas negras corresponden a gneises bandeados paleoproterozoicos de la Zona Canteras-Puerto Peñasco. En los diagramas, el campo gris claro representa granitoides paleoproterozoicos del bloque Caborca en la región de Quitovac y representando, por correlación, a la Provincia Yavapai del SW de USA. Por su parte, el campo gris oscuro corresponde a granitoides del bloque "Norte América" en la misma región, correlacionados con la Provincia Mazatzal (Iriondo et al., 2004). (A) Diagrama de Peccerillo y Taylor $\left(1976 ; \mathrm{K}_{2} \mathrm{O}\right.$ vs. $\mathrm{SiO}_{2}$ ) que muestra las diferentes series magmáticas calcoalcalinas

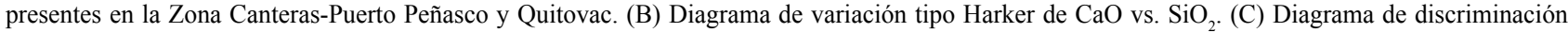
tectonomagmática para granitos según Pearce et al. (1984). Ambiente tectónico para los granitoides en la región de Quitovac y Zona Canteras-Puerto Peñasco en el NW de Sonora, México. Abreviaciones para los campos: VAG, Volcanic Arc Granites = Granitos de Arco Volcánico; WPG, Within-Plate Granites $=$ Granitos de Intraplaca; ORG, Ocean-Ridge Granites = Granitos de Dorsal Oceánica. 
normalización con estándares, mediciones de control, estándares isotópicos internos del laboratorio, cálculo de errores, entre otros, se recomienda consultar la siguiente página web: http://www.geologia.unam.mx/geoq/lugis/espectrometria1.pdf. Cabe señalar que al pie de la Tabla 7 se presentan algunos de estos datos.

\subsection{Isótopos de Lu-Hf en zircones}

Los análisis isotópicos de Lu-Hf en zircones se llevaron a cabo en el Departamento de Ciencias Geológicas de la Universidad de Florida en Gainesville, EUA, utilizando un espectrómetro de masas de tipo multicolector con plasma de acoplamiento inductivo marca Nu Plasma (Multi-Collector Inductively Coupled Plasma Mass Spectrometry, MC-ICPMS) equipado con 3 contadores de iones y 12 detectores Faraday. La ablación se llevó a cabo por alrededor de 30 segundos con el fin de minimizar la profundidad del hoyo de ablación y el fraccionamiento elemental. La mayoría de los análisis de Lu-Hf se llevaron a cabo con un haz de $\sim 50-60 \mu \mathrm{m}$ de diámetro creando un hoyo de $\sim 40-50 \mu \mathrm{m}$ de profundidad.

Las medidas isotópicas de Lu-Hf a partir de zircones fueron obtenidas en modo estático en los detectores Faraday obteniendo simultáneamente ${ }^{180} \mathrm{Hf},{ }^{178} \mathrm{Hf},{ }^{177} \mathrm{Hf},{ }^{176} \mathrm{Hf},{ }^{175} \mathrm{Lu}$, ${ }^{174} \mathrm{Hf} \mathrm{y}{ }^{172} \mathrm{Yb}$. Los análisis fueron realizados corrigiendo la interferencia isobárica de $\mathrm{Lu}$ e $\mathrm{Yb}$ en línea, usando ${ }^{176} \mathrm{Lu} /$ ${ }^{175} \mathrm{Lu}=0.02653 \mathrm{e}{ }^{176} \mathrm{Yb} /{ }^{172} \mathrm{Yb}=0.5870$, ambas relaciones encontrándose dentro del intervalo de valores publicados (Vervoort et al., 2004). Todas las relaciones isotópicas, incluyendo $\mathrm{Lu}$ y $\mathrm{Yb}$, fueron corregidas por fraccionamiento de masas ("mass-bias") usando la relación isotópica ${ }^{178} \mathrm{Hf} /{ }^{177} \mathrm{Hf}$ $=1.46718$. Múltiples análisis de FC-1 (zircón estándar) dieron un resultado de ${ }^{176} \mathrm{Hf} /{ }^{177} \mathrm{Hf}=0.282169( \pm 0.000032$; 2 sigma; $\mathrm{n}=150$ ) indistinguible del análisis líquido por dilución isotópica de este estándar de ${ }^{176} \mathrm{Hf} /{ }^{177} \mathrm{Hf}=0.282174$ ( $\pm 0.000013 ; 2$ sigma) y también de los resultados recientemente publicados por Woodhead y Hergt (2005) de ${ }^{176} \mathrm{Hf} /{ }^{177} \mathrm{Hf}=0.282172( \pm 0.000042 ; 2$ sigma $)$. Las relaciones medidas y corregidas de ${ }^{176} \mathrm{Lu} /{ }^{177} \mathrm{Hf}$ por fraccionamiento de masas ("mass-bias") fueron utilizadas, junto con las edades ${ }^{207} \mathrm{~Pb} /{ }^{206} \mathrm{~Pb}$ de cada zircón, para calcular las relaciones iniciales de ${ }^{176} \mathrm{Hf} /{ }^{177} \mathrm{Hf}$, según Griffin et al. (2002). En general, debido a las muy bajas relaciones de Lu/Hf, la diferencia entre la relación medida y las relaciones iniciales calculadas de ${ }^{176} \mathrm{Hf} /{ }^{177} \mathrm{Hf}$ en la mayoría de los casos es menor que 1 épsilon.

La constante de decaimiento de ${ }^{176} \mathrm{Lu}$ utilizada en este estudio es de $1.865 \times 10^{-11}$ años $^{-1}$, según Scherer et al. (2001) y Soderlund et al. (2004). Las relaciones iniciales de ${ }^{176} \mathrm{Hf} /{ }^{177} \mathrm{Hf}_{\mathrm{CHUR}}$ y los valores de épsilon $\mathrm{Hf}$ iniciales $(\mathrm{t})$ fueron calculados utilizando los valores condríticos de ${ }^{176} \mathrm{Hf} /{ }^{177} \mathrm{Hf}=$ $0.282772 \mathrm{y}^{176} \mathrm{Lu} /{ }^{177} \mathrm{Hf}=0.0332$ propuestos por Blichert-Toft y Albarede (1997) con referencia al reservorio condrítico (CHUR) al tiempo de crecimiento del zircón de un magma.

Para el cálculo de las edades modelo Hf $\left(\mathrm{T}_{\mathrm{DM}}\right)$ en un paso ("single-stage model ages") se empleó un modelo de evolución del manto empobrecido calculado a partir de valores actuales de ${ }^{176} \mathrm{Hf} /{ }^{177} \mathrm{Hf}=0.28325$, similar al valor promedio de MORB (Nowell et al., 1998) y de ${ }^{176} \mathrm{Lu} /{ }^{177} \mathrm{Hf}$ $=0.0384$ (Griffin et al., 2000); esto es similar, aunque no idéntico, a la curva del manto empobrecido definida por rocas juveniles a través del tiempo (Vervoort y BlichertToft, 1999).

Las edades modelo de $\mathrm{Hf}\left(\mathrm{T}_{\mathrm{DM}}\right)$ en un paso ("single-stage model ages"), las cuales son calculadas usando la relación ${ }^{176} \mathrm{Lu} /{ }^{177} \mathrm{Hf}$ medida del zircón, proporcionan sólo una edad mínima para la fuente del magma del cual el zircón ha cristalizado. Por lo tanto, también se ha calculado, para cada zircón, una "edad modelo cortical" (edades modelo en dos pasos), la cual asume que la fuente del magma fue producida de una corteza continental promedio (máfica, intermedia o félsica) que originalmente fue derivada del manto empobrecido. Las edades modelo $\mathrm{Hf}\left(\mathrm{T}_{\mathrm{DMC}}\right)$ en dos pasos ("two-stage model ages") fueron calculadas para la roca fuente del magma asumiendo valores de ${ }^{176} \mathrm{Lu} /{ }^{177} \mathrm{Hf}=$ 0.010 de una corteza félsica promedio (Amelin et al., 1999), ${ }^{176} \mathrm{Lu} /{ }^{177} \mathrm{Hf}=0.015$ de una corteza intermedia promedio (Griffin et al., 2002) y, por último, ${ }^{176} \mathrm{Lu} /{ }^{177} \mathrm{Hf}=0.022 \mathrm{de}$ una corteza máfica promedio (Vervoort y Patchett, 1996).

\section{Resultados}

\subsection{Geocronología U-Pb en zircones}

Dos muestras de rocas de la Zona Canteras-Puerto Peñasco fueron fechadas por el método geocronológico U$\mathrm{Pb}$ en zircones para determinar la edad de cristalización, utilizando la técnica LA-MC-ICPMS (Laser Ablation-Multicollector-Inductively Coupled Plasma Mass Spectrometry; Ablación láser acoplado a espectrómetro de masas de tipo multicolector con plasma de acoplamiento inductivo). A continuación, se describen los datos geocronológicos $\mathrm{U}-\mathrm{Pb}$ para cada muestra reportando los resultados en la Tabla 3 y en la Figura 4. Imágenes de catodoluminiscencia de zircones de cada muestra fechada se encuentran reportadas en ArvizuGutiérrez (2008), con la excepción de algunas imágenes de catodoluminiscencia de zircones mostradas en el apartado de estudios de Lu-Hf en zircones.

El gneis bandeado PIN-07-22, recolectado en la Zona Canteras-Puerto Peñasco (Figuras 2A y 2B), presentó un gran número de zircones en el proceso de separación mineral. Una población de 50 de estos zircones muestra edades bastante homogéneas, sin presentar importantes cantidades de zircones heredados (Figura 4A; Tabla 3). Los datos U-Pb de zircones graficados en el diagrama de Tera-Wasserburg (Figura 4A) muestran que 29 de esos análisis (elipses de color gris) son concordantes y forman una agrupación que permite obtener una edad ${ }^{207} \mathrm{~Pb} /{ }^{206} \mathrm{~Pb}$ media ponderada de $1764 \pm 3$ Ma (2-sigma; MSWD = 1.3).

Esta edad media ponderada se interpreta como la edad de cristalización del protolito del gneis bandeado. Estos datos concordantes son los que se utilizaron para el cálculo 

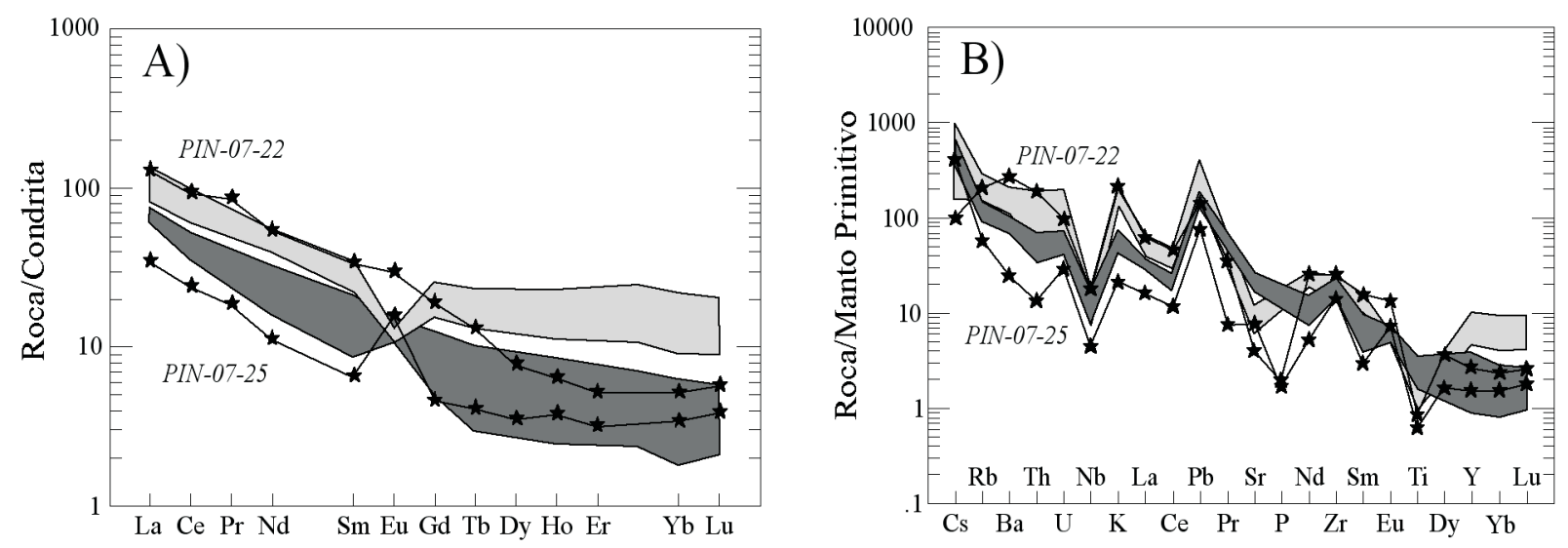

Figura 6. Diagramas de tierras raras (REE, Rare Earth Elements) y multielementos para granitoides de la región de Quitovac y gneises bandeados de la Zona Canteras-Puerto Peñasco en el NW de Sonora, México. (A) Diagrama de tierras raras normalizadas a condrita (Nakamura, 1974). (B) Diagrama multielementos normalizado a Manto Primitivo (Sun y McDonough, 1989). En los diagramas, las estrellas negras representan rocas paleoproterozoicas de la Zona Canteras-Puerto Peñasco; por su parte, los campos gris claro y gris oscuro corresponden a rocas del bloque Caborca (Yavapai) y bloque "Norte América" (Mazatzal), respectivamente (campos a partir de datos de Iriondo et al., 2004).

estadístico mostrado en el gráfico de media ponderada de la Figura 4C. Por otro lado, se cuenta con una población de zircones con aparente pérdida de $\mathrm{Pb}$ (elipses de color verde) que son descartados para el cálculo de edad. Se observa que la totalidad de los análisis permite generar una línea de discordia con intersecciones a $1772 \pm 13$ Ma y a 231 $\pm 180 \mathrm{Ma}$ (Figura 4A). Esta última edad de intersección inferior podría interpretarse como la edad del evento que ha producido la pérdida de $\mathrm{Pb}$ de algunos de los zircones de esta roca. De la misma manera, análisis que pudieran corresponder a zircones heredados (elipses de color negro), o que mostraran altos porcentajes de discordancia ( $>4 \%)$, también son descartados para calcular la edad media ponderada (Figuras 4A y C).

Una segunda muestra de gneis bandeado (PIN-07-25) de la Zona Canteras-Puerto Peñasco (Figuras 2A y 2B) fue fechada por el método U-Pb utilizando 50 análisis de zircones (Tabla 3). En el diagrama de Tera-Wasserburg (Figura 4D) observamos que 12 de estos análisis (elipses de color gris) forman una agrupación de zircones concordantes que empleamos para calcular la edad ${ }^{207} \mathrm{~Pb} /{ }^{206} \mathrm{~Pb}$ media ponderada de $1725 \pm 3 \mathrm{Ma}(2$-sigma; $\mathrm{MSWD}=1.8)$. Esta edad se interpreta como la edad de cristalización del protolito de este gneis bandeado. Los datos representados por las elipses de color negro son datos de zircones que presentan un pequeño grado de herencia haciéndolos un poco más viejos que los cristales de zircón asociados a la cristalización magmática. Estos datos y los datos representados en elipses de color verde, que representan análisis con zircones que han sufrido diferentes grados de pérdida de $\mathrm{Pb}$, no fueron empleados para el cálculo de la edad media ponderada (Figuras 4D y F). Se observa que los 50 datos de zircones proporcionan una línea de discordia con intercepciones superior de $1872 \pm 83 \mathrm{Ma}$ e inferior de $1237 \pm 160 \mathrm{Ma}$ (Figura 4D).
Esta edad de intersección inferior con la concordia podría representar la edad del pulso magmático y/o metamórfico que propicio la pérdida de $\mathrm{Pb}$ en algunos zircones de esta muestra de gneis bandeado. También cabe destacar que ambos gneises bandeados de la Zona Canteras-Puerto Peñasco tienen edades diferentes dentro de los límites de error para las edades medias ponderadas reportadas para ambas rocas.

\subsection{Estudios geoquímicos}

Los resultados geoquímicos obtenidos por Fluorescencia de Rayos X (FRX) para los elementos mayores de las rocas de la Zona Canteras-Puerto Peñasco, así como los datos analíticos de elementos traza y tierras raras obtenidos por espectrometría de masas con plasma de acoplamiento inductivo (ICP-MS), están listados en las Tablas 4 y 5 . En la Tabla 6 presentamos las características geoquímicas principales de las rocas paleoproterozoicas de la región de Quitovac (Iriondo et al., 2004) para hacer una comparación con la de los gneises de la Zona Canteras-Puerto Peñasco. Las metodologías y procedimientos de las técnicas analíticas empleadas y la descripción más detallada de los datos geoquímicos de las rocas de la Zona Canteras-Puerto Peñasco se encuentran en Arvizu-Gutiérrez (2008).

\subsubsection{Geoquímica de elementos mayores}

Dos muestras de gneises paleoproterozoicos de la Zona Canteras-Puerto Peñasco fueron analizadas, las cuales contienen altos porcentajes de sílice $(75.90 \mathrm{wt}$. \% para la muestra PIN-07-22 y 78.65 wt. \% para la PIN07-25).Los valores altos de $\mathrm{SiO}_{2}$ para estas muestras pudieran deberse a una alta recristalización-silicificación durante el proceso metamórfico de gneisificación. 


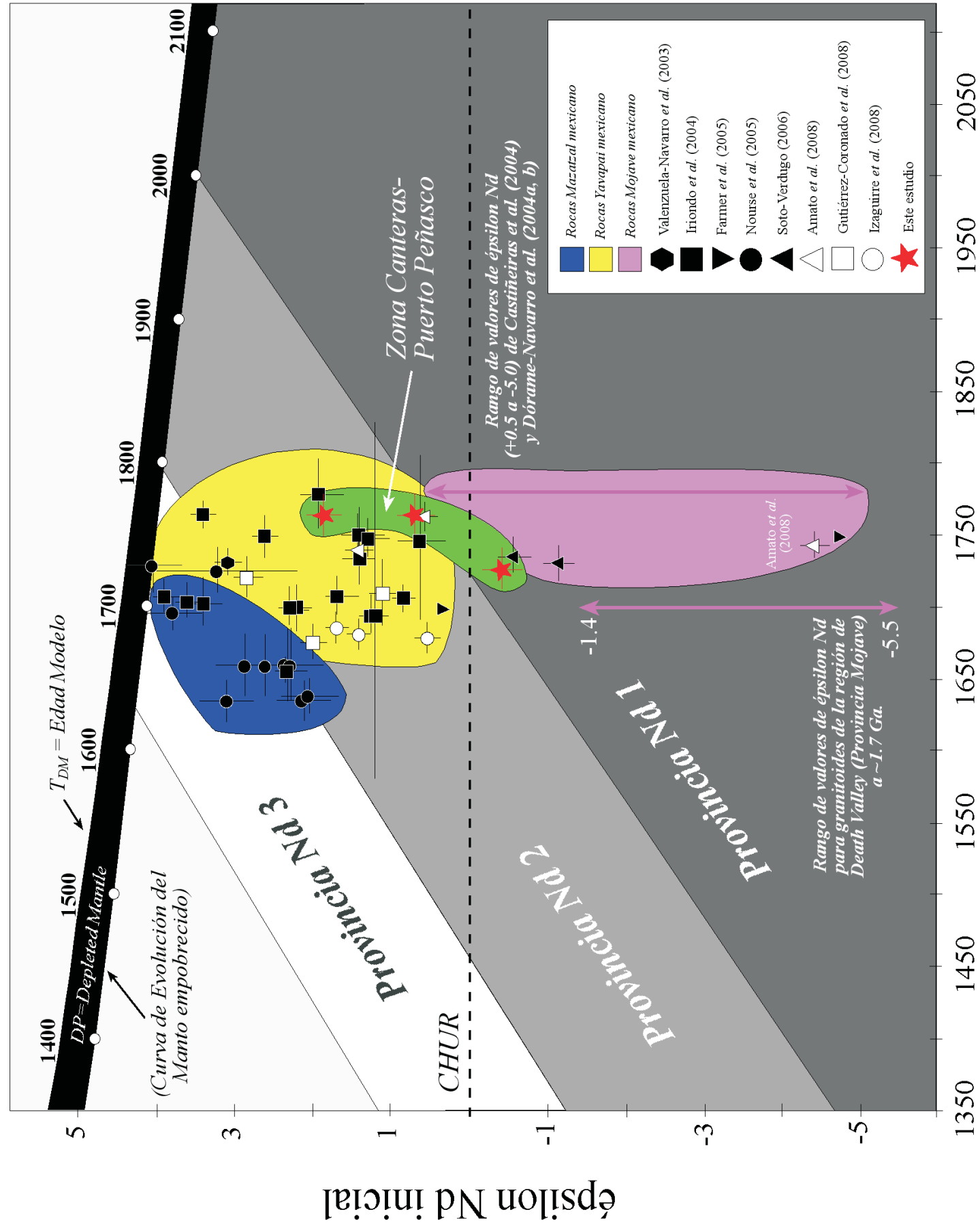

용

究

言 웡

กิ

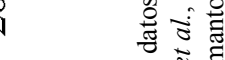

울 응

흘

和高

o 웅



원

要

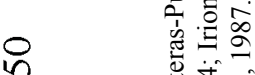

D

(ิ)

중

$\sum$ 政

乙

증

구

育它:

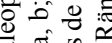

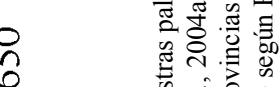

-

范范迹

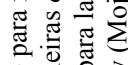

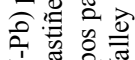

光

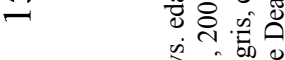

गे क्षे

Z ธ

흐류

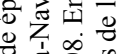

¿

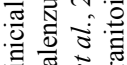

西

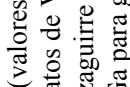

艺芯

艺

:0ิ

导。

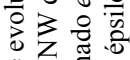

ष

్ㅐㄴ.

需

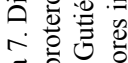

펼 융 
En la Figura 5A se puede observar una gran diferencia entre estas dos muestras de gneises con respecto a su contenido de $\mathrm{K}_{2} \mathrm{O}$. La muestra PIN-07-22 tiene un alto contenido en $\mathrm{K}_{2} \mathrm{O}$ (6.35 wt. \%) graficando en la línea límite entre los campos shoshonítico y calcoalcalino alto en $\mathrm{K}$, mientras que la PIN-07-25 presenta un valor muy bajo con respecto a la anterior $(0.65 \mathrm{wt}$ \% \% y tiene más afinidad con la serie magmática calcoalcalina baja en $\mathrm{K}$.

En el diagrama tipo Harker de $\mathrm{CaO}$ vs. $\mathrm{SiO}_{2}$ (Figura 5B) se puede observar que la muestra PIN-07-25 muestra un claro enriquecimiento en $\mathrm{Ca}$ con respecto a la PIN-07-22. Esto es un claro ejemplo de que el $\mathrm{K}$ y Ca junto con algunos otros elementos químicos son muy móviles durante procesos de alteración y/o metamorfismo de alto grado.

\subsubsection{Geoquímica de elementos traza y tierras raras}

En el diagrama de discriminación tectonomagmática de formación de granitos $\mathrm{Y} v \mathrm{vs}$. $\mathrm{Nb}$ (Figura 5C) se muestra que las dos rocas paleoproterozoicas de la Zona Canteras-Puerto Peñasco caen en el campo de granitos de arco volcánico.

En el diagrama de REE normalizadas a condrita (Nakamura, 1974; Figura 6A) se observa claramente que para las muestras PIN-07-22 y PIN-07-25, existe un enriquecimiento de las tierras raras ligeras ( $\mathrm{La}, \mathrm{Ce}, \mathrm{Pr}, \mathrm{Nd}$; LREE: Light Rare Earth Elements) con respecto a las tierras raras pesadas (Er, Yb, Lu; HREE: Heavy Rare Earth Elements). También se puede ver que la muestra PIN-07-25 está más empobrecida en LREE y HREE en comparación con la PIN07-22; esto se puede observar muy bien en el valor total de tierras raras y el valor de $(\mathrm{La} / \mathrm{Yb})_{\mathrm{N}}($ Tabla 4$)$. Los valores para la PIN-07-22 son $\sum \mathrm{REE}=186.14 \mathrm{y}(\mathrm{La} / \mathrm{Yb})_{\mathrm{N}}=25.472$, mientras que para la PIN-07-25 son $\sum \mathrm{REE}=47.80 \mathrm{y}(\mathrm{La} /$ $\mathrm{Yb})_{\mathrm{N}}=10.165$. En ambas muestras se observan anomalías positivas de Eu; para la muestra PIN-07-25 la anomalía es muy distinguible con un valor de $\mathrm{Eu} / \mathrm{Eu}^{*}=2.873$, y para la muestra PIN-07-22 no es muy notoria teniendo un valor de $\mathrm{Eu} / \mathrm{Eu}^{*}=1.149$. Podríamos explicar estas anomalías positivas de Eu por la acumulación de cristales de plagioclasa en el magma, que se justifica por los valores altos de $\mathrm{CaO}$ y $\mathrm{Na}_{2} \mathrm{O}$, sobre todo para la muestra PIN-07-25.

En el diagrama multielementos (Figura 6B), apreciamos que para las dos muestras de la Zona Canteras-Puerto Peñasco, existe un enriquecimiento de los elementos $\mathrm{Cs}, \mathrm{Rb}$, $\mathrm{Ba}, \mathrm{K}, \mathrm{Sr}$, Eu y $\mathrm{Pb}$ con respecto a las REE y a los elementos $\mathrm{Y}, \mathrm{Hf}, \mathrm{Zr}, \mathrm{Ti}, \mathrm{Ta}, \mathrm{Nb}$ y P; este mismo comportamiento se puede observar de igual manera para los campos generados a partir de las rocas de la región de Quitovac. Otras de las características claras en el diagrama multielementos son las anomalías negativas notables de $\mathrm{Nb}$, Py Ti para las muestras de la Zona Canteras-Puerto Peñasco, y anomalías positivas de $\mathrm{K}$ y $\mathrm{Pb}$ para las mismas.

\subsection{Estudios isotópicos de $\mathrm{Sm}-\mathrm{Nd}$ en roca total}

Tres muestras de gneises bandeados paleoproterozoicos de la Zona Canteras-Puerto Peñasco (Figuras 2A y 2B) fueron analizadas isotópicamente utilizando el método $\mathrm{Sm}-\mathrm{Nd}$ en roca total con el fin de obtener información petrogenética sobre el origen de estas rocas. Los datos analíticos están reportados en la Tabla 7 y graficados en la Figura 7.

Para las muestras de gneises PIN-07-22 y PIN-07-25, fechadas por el método $\mathrm{U}-\mathrm{Pb}$ en zircones en este estudio (1764 \pm 3 Ma y $1725 \pm 3 \mathrm{Ma}$, respectivamente), se obtuvieron valores iniciales de épsilon $\mathrm{Nd} \mathrm{de}+0.66$ y -0.57 con correspondientes edades modelo $\mathrm{Nd}\left(\mathrm{T}_{\mathrm{DM}}\right)$ de 1.97 y 2.02 $\mathrm{Ga}$. Una tercera muestra, no fechada, de gneis bandeado (PIN-07-21), de la que se infiere una edad similar a la de la muestra PIN-07-22 por correlación litológica, presenta un valor de épsilon $\mathrm{Nd}$ inicial de +1.86 con una edad modelo $\mathrm{Nd}$ $\left(\mathrm{T}_{\mathrm{DM}}\right)$ de $1.91 \mathrm{Ga}$. Los valores iniciales de épsilon Nd para las muestras PIN-07-21 y PIN-07-22 indican que estas dos rocas son isotópicamente más empobrecidas con respecto a la muestra PIN-07-25, la cual sugiere un ligero aporte de material cortical.

Los resultados isotópicos $\mathrm{Sm}-\mathrm{Nd}$ son ilustrados en un diagrama de evolución del $\mathrm{Nd}$ donde se grafican los valores iniciales de épsilon $\mathrm{Nd}$ contra la edad $\mathrm{U}-\mathrm{Pb}$ en zircones de cada roca (Figura 7). Dos de las tres muestras caen en el campo de la Provincia Nd 2 (Yavapai), mientras que la muestra PIN-07-25 cae en el campo de la Provincia Nd 1 (Mojave) pero relativamente cerca del campo de $\mathrm{Nd} 2$ (Yavapai).

En el gráfico de evolución del Nd de la Figura 7 se reportan los datos isotópicos $\mathrm{Sm}-\mathrm{Nd}$ de rocas de basamento paleoproterozoico del NW de Sonora compilados de la literatura y que mencionamos anteriormente (Valenzuela-Navarro et al., 2003; Castiñeiras et al., 2004a, b; Dórame-Navarro et al., 2004; Iriondo et al., 2004; Farmer et al., 2005; Nourse et al., 2005; Soto-Verdugo, 2006; Amato et al., 2008; Gutiérrez-Coronado et al., 2008; Izaguirre et al., 2008).

\subsection{Estudios isotópicos de Lu-Hf en zircones}

Las dos muestras de gneises de la Zona Canteras-Puerto Peñasco fueron analizadas para determinar las composiciones isotópicas de $\mathrm{Lu}-\mathrm{Hf}$ en zircones (valores de épsilon $\mathrm{Hf}$ inicial y edades modelo $\mathrm{Hf}_{\mathrm{DM}}$ en un paso y dos pasos respecto al manto empobrecido). Los datos isotópicos se presentan en la Tabla 8 , y se encuentran graficados en las Figuras 8 y 9.

La muestra PIN-07-22 de gneis cuarzo-feldespático de biotita-moscovita tiene una edad ${ }^{207} \mathrm{~Pb} /{ }^{206} \mathrm{~Pb}$ en zircones de $1764 \pm 3 \mathrm{Ma}$ (2 sigma; Figura 4A y Tabla 3). Para esta muestra se analizaron un total de trece granos de zircón para realizar los estudios isotópicos de Lu-Hf en los que previamente se habían realizado los estudios geocronológicos de $\mathrm{U}-\mathrm{Pb}$. Los trece análisis proporcionan un valor épsilon $\mathrm{Hf}$ inicial medio ponderado de $3.50 \pm 0.54(\mathrm{MSWD}=0.45 ; \mathrm{n}=$ 13; Figura 8A) y edades modelo $\mathrm{Hf}\left(\mathrm{T}_{\mathrm{DM}}\right)$ en un paso en relación al manto empobrecido entre 2.02-2.12 Ga mostradasen el histograma de la Figura 8B y edades modelo $\mathrm{Hf}\left(\mathrm{T}_{\mathrm{DM} 2}{ }^{\mathrm{C}}\right.$; 
Tabla 3. Datos analíticos U-Pb por LA-MC-ICPMS de zircones de rocas paleoproterozoicas de la Zona Canteras-Puerto Peñasco, NW Sonora, México.

\begin{tabular}{|c|c|c|c|c|c|c|c|c|c|c|c|}
\hline $\begin{array}{l}\text { Número de } \\
\text { Punto }\end{array}$ & Comentarios & $\begin{array}{l}{ }^{207} \mathrm{~Pb} / \\
{ }^{206} \mathrm{~Pb}^{*}\end{array}$ & $\begin{array}{l}\text { error } \\
(\%)\end{array}$ & $\begin{array}{l}{ }^{207} \mathrm{~Pb} / \\
{ }^{235} \mathrm{U}^{*}\end{array}$ & $\begin{array}{l}\text { error } \\
(\%)\end{array}$ & $\begin{array}{l}{ }^{206} \mathrm{~Pb} / \\
{ }^{238} \mathrm{U}^{*}\end{array}$ & $\begin{array}{l}\text { error } \\
\%\end{array}$ & $\begin{array}{l}\text { error } \\
\text { correl }\end{array}$ & $\begin{array}{c}(\%) \\
\text { discor. \# }\end{array}$ & $\begin{array}{c}{ }^{207} \mathrm{~Pb} /{ }^{206} \mathrm{~Pb} \\
\mathrm{Edad} \\
(\mathrm{Ma})\end{array}$ & $\begin{array}{l}\text { error } \\
\text { (Ma) }\end{array}$ \\
\hline $\begin{array}{l}\text { M u e s t r a } \\
\text { PIN-07-22 }\end{array}$ & Gneis bandeado & \multicolumn{4}{|c|}{ (Zona Canteras-Puerto Peñasco) } & \multicolumn{4}{|c|}{ Probeta HARIM-2 (Abril 08) } & & \\
\hline PIN_22_13 & núcleo. $>4 \%$ discord. & $0.1024 \pm$ & 0.3 & $3.42 \pm$ & 3.0 & $0.2423 \pm$ & 3.0 & 0.995 & 7 & $1667.0 \pm$ & 5.3 \\
\hline PIN_22_45 & núcleo, pérdida de $\mathrm{Pb}$ & $0.1035 \pm$ & 0.3 & $4.03 \pm$ & 1.6 & $0.2825 \pm$ & 1.5 & 0.980 & 2 & $1687.5 \pm$ & 5.7 \\
\hline PIN_22_35 & núcleo, pérdida de $\mathrm{Pb}$ & $0.1048 \pm$ & 0.4 & $4.62 \pm$ & 3.0 & $0.3194 \pm$ & 3.0 & 0.991 & -2 & $1710.5 \pm$ & 7.5 \\
\hline PIN_22_44 & borde, pérdida de $\mathrm{Pb}$ & $0.1051 \pm$ & 0.4 & $4.52 \pm$ & 2.9 & $0.3121 \pm$ & 2.8 & 0.990 & -1 & $1716.5 \pm$ & 7.3 \\
\hline PIN_22_17 & borde, $>4 \%$ discord. & $0.1052 \pm$ & 0.3 & $3.24 \pm$ & 5.5 & $0.2233 \pm$ & 5.5 & 0.999 & 11 & $1718.5 \pm$ & 5.4 \\
\hline PIN_22_16 & borde, pérdida de $\mathrm{Pb}$ & $0.1055 \pm$ & 0.5 & $4.36 \pm$ & 3.0 & $0.2994 \pm$ & 3.0 & 0.986 & 1 & $1723.5 \pm$ & 9.0 \\
\hline PIN_22_29 & borde, pérdida de $\mathrm{Pb}$ & $0.1061 \pm$ & 0.5 & $4.45 \pm$ & 2.1 & $0.3043 \pm$ & 2.0 & 0.964 & 0 & $1733.0 \pm$ & 10.0 \\
\hline PIN_22_40 & núcleo, pérdida de $\mathrm{Pb}$ & $0.1064 \pm$ & 0.3 & $4.13 \pm$ & 5.0 & $0.2816 \pm$ & 4.9 & 0.998 & 4 & $1738.0 \pm$ & 5.8 \\
\hline PIN_22_18 & borde & $0.1069 \pm$ & 0.5 & $4.37 \pm$ & 1.7 & $0.2964 \pm$ & 1.7 & 0.964 & 2 & $1747.0 \pm$ & 8.3 \\
\hline PIN_22_34 & núcleo & $0.1070 \pm$ & 0.4 & $4.87 \pm$ & 2.9 & $0.3304 \pm$ & 2.9 & 0.993 & -2 & $1748.0 \pm$ & 6.4 \\
\hline PIN_22_20 & borde & $0.1072 \pm$ & 0.3 & $4.67 \pm$ & 2.3 & $0.3158 \pm$ & 2.3 & 0.991 & -1 & $1753.0 \pm$ & 5.7 \\
\hline PIN_22_37 & núcleo & $0.1075 \pm$ & 0.3 & $4.85 \pm$ & 1.6 & $0.3273 \pm$ & 1.6 & 0.982 & -2 & $1756.5 \pm$ & 5.6 \\
\hline PIN_22_26 & núcleo & $0.1075 \pm$ & 0.4 & $4.24 \pm$ & 2.0 & $0.2861 \pm$ & 1.9 & 0.975 & 3 & $1757.5 \pm$ & 8.1 \\
\hline PIN_22_19 & núcleo & $0.1075 \pm$ & 0.3 & $4.76 \pm$ & 2.2 & $0.3212 \pm$ & 2.2 & 0.988 & -1 & $1758.0 \pm$ & 6.2 \\
\hline PIN_22_27 & núcleo & $0.1076 \pm$ & 0.3 & $4.74 \pm$ & 1.9 & $0.3197 \pm$ & 1.8 & 0.983 & -1 & $1758.5 \pm$ & 6.3 \\
\hline PIN_22_12 & borde & $0.1076 \pm$ & 0.3 & $4.67 \pm$ & 1.9 & $0.3151 \pm$ & 1.9 & 0.984 & 0 & $1759.0 \pm$ & 6.3 \\
\hline PIN_22_14 & borde & $0.1076 \pm$ & 0.3 & $4.52 \pm$ & 2.5 & $0.3050 \pm$ & 2.5 & 0.991 & 1 & $1759.0 \pm$ & 6.3 \\
\hline PIN_22_33 & borde & $0.1076 \pm$ & 0.4 & $4.74 \pm$ & 2.4 & $0.3197 \pm$ & 2.3 & 0.987 & -1 & $1759.0 \pm$ & 7.1 \\
\hline PIN_22_43 & núcleo & $0.1076 \pm$ & 0.3 & $4.59 \pm$ & 1.7 & $0.3095 \pm$ & 1.7 & 0.981 & 0 & $1759.0 \pm$ & 6.2 \\
\hline PIN_22_50 & borde & $0.1076 \pm$ & 0.3 & $4.52 \pm$ & 1.6 & $0.3049 \pm$ & 1.6 & 0.984 & 1 & $1759.0 \pm$ & 5.3 \\
\hline PIN_22_41 & núcleo & $0.1077 \pm$ & 0.3 & $4.42 \pm$ & 2.7 & $0.2978 \pm$ & 2.7 & 0.993 & 2 & $1760.5 \pm$ & 5.7 \\
\hline PIN_22_3 & borde & $0.1077 \pm$ & 0.4 & $4.39 \pm$ & 1.9 & $0.2953 \pm$ & 1.9 & 0.979 & 2 & $1761.0 \pm$ & 7.0 \\
\hline PIN_22_28 & borde & $0.1078 \pm$ & 0.4 & $4.95 \pm$ & 2.9 & $0.3329 \pm$ & 2.9 & 0.991 & -2 & $1762.0 \pm$ & 7.2 \\
\hline PIN_22_2 & núcleo & $0.1079 \pm$ & 0.3 & $4.58 \pm$ & 1.8 & $0.3077 \pm$ & 1.8 & 0.990 & 1 & $1763.5 \pm$ & 4.6 \\
\hline PIN_22_21 & núcleo & $0.1079 \pm$ & 0.3 & $4.70 \pm$ & 1.5 & $0.3158 \pm$ & 1.5 & 0.981 & 0 & $1763.5 \pm$ & 5.4 \\
\hline PIN_22_47 & núcleo & $0.1079 \pm$ & 0.3 & $4.55 \pm$ & 1.5 & $0.3059 \pm$ & 1.5 & 0.980 & 1 & $1763.5 \pm$ & 5.4 \\
\hline PIN_22_24 & núcleo & $0.1080 \pm$ & 0.3 & $4.77 \pm$ & 1.7 & $0.3201 \pm$ & 1.7 & 0.984 & -1 & $1765.5 \pm$ & 5.7 \\
\hline PIN_22_1 & núcleo & $0.1080 \pm$ & 0.3 & $4.70 \pm$ & 2.8 & $0.3156 \pm$ & 2.8 & 0.995 & 0 & $1766.0 \pm$ & 5.2 \\
\hline PIN_22_25 & borde & $0.1080 \pm$ & 0.4 & $4.44 \pm$ & 1.5 & $0.2978 \pm$ & 1.5 & 0.970 & 2 & $1766.5 \pm$ & 6.8 \\
\hline PIN_22_38 & borde & $0.1081 \pm$ & 0.3 & $4.70 \pm$ & 2.3 & $0.3156 \pm$ & 2.2 & 0.989 & 0 & $1767.5 \pm$ & 6.2 \\
\hline PIN_22_4 & borde & $0.1082 \pm$ & 0.2 & $4.64 \pm$ & 1.5 & $0.3109 \pm$ & 1.5 & 0.988 & 1 & $1769.5 \pm$ & 4.1 \\
\hline PIN_22_7 & borde & $0.1082 \pm$ & 0.2 & $4.64 \pm$ & 1.7 & $0.3108 \pm$ & 1.7 & 0.992 & 1 & $1769.5 \pm$ & 4.0 \\
\hline PIN_22_22 & núcleo & $0.1083 \pm$ & 0.3 & $4.61 \pm$ & 1.5 & $0.3086 \pm$ & 1.5 & 0.976 & 1 & $1770.0 \pm$ & 6.0 \\
\hline PIN_22_15 & borde & $0.1083 \pm$ & 0.4 & $4.64 \pm$ & 2.1 & $0.3108 \pm$ & 2.1 & 0.982 & 1 & $1770.5 \pm$ & 7.4 \\
\hline PIN_22_42 & núcleo & $0.1084 \pm$ & 0.3 & $4.44 \pm$ & 4.7 & $0.2968 \pm$ & 4.7 & 0.997 & 2 & $1772.5 \pm$ & 6.3 \\
\hline PIN_22_9 & borde & $0.1084 \pm$ & 0.2 & $4.26 \pm$ & 1.5 & $0.2846 \pm$ & 1.5 & 0.989 & 4 & $1773.0 \pm$ & 4.0 \\
\hline PIN_22_30 & borde & $0.1085 \pm$ & 0.3 & $4.72 \pm$ & 1.8 & $0.3153 \pm$ & 1.7 & 0.980 & 0 & $1774.0 \pm$ & 6.4 \\
\hline PIN_22_5 & núcleo, herencia & $0.1090 \pm$ & 0.2 & $4.60 \pm$ & 1.5 & $0.3059 \pm$ & 1.4 & 0.990 & 2 & $1782.0 \pm$ & 3.8 \\
\hline PIN_22_49 & núcleo, herencia, $>4 \%$ discord. & $0.1092 \pm$ & 0.4 & $4.17 \pm$ & 1.9 & $0.2770 \pm$ & 1.9 & 0.982 & 5 & $1785.0 \pm$ & 6.7 \\
\hline PIN_22_11 & núcleo, $>4 \%$ discord. & $0.1092 \pm$ & 0.4 & $4.12 \pm$ & 1.4 & $0.2737 \pm$ & 1.3 & 0.963 & 6 & $1786.5 \pm$ & 6.7 \\
\hline PIN_22_8 & núcleo, herencia & $0.1094 \pm$ & 0.3 & $5.34 \pm$ & 2.5 & $0.3543 \pm$ & 2.5 & 0.995 & -4 & $1788.5 \pm$ & 4.6 \\
\hline PIN_22_31 & borde, herencia & $0.1098 \pm$ & 0.3 & $4.68 \pm$ & 1.7 & $0.3089 \pm$ & 1.7 & 0.981 & 1 & $1796.0 \pm$ & 6.0 \\
\hline PIN_22_10 & núcleo, herencia & $0.1099 \pm$ & 0.4 & $4.69 \pm$ & 2.3 & $0.3093 \pm$ & 2.3 & 0.984 & 1 & $1797.0 \pm$ & 7.5 \\
\hline PIN_22_36 & núcleo, alto ${ }^{204} \mathrm{~Pb}$ & $0.1102 \pm$ & 0.4 & $4.71 \pm$ & 3.3 & $0.3098 \pm$ & 3.3 & 0.994 & 2 & $1802.0 \pm$ & 6.7 \\
\hline
\end{tabular}


Tabla 3. Datos analíticos U-Pb por LA-MC-ICPMS de zircones de rocas paleoproterozoicas de la Zona Canteras-Puerto Peñasco, NW Sonora, México. (Cont.)

\begin{tabular}{|c|c|c|c|c|c|c|c|c|c|c|c|}
\hline $\begin{array}{l}\text { Número de } \\
\text { Punto }\end{array}$ & Comentarios & $\begin{array}{l}{ }^{207} \mathrm{~Pb} / \\
{ }^{206} \mathrm{~Pb}^{*}\end{array}$ & $\begin{array}{l}\text { error } \\
(\%)\end{array}$ & $\begin{array}{l}{ }^{207} \mathrm{~Pb} / \\
{ }^{235} \mathrm{U}^{*}\end{array}$ & $\begin{array}{l}\text { error } \\
(\%)\end{array}$ & $\begin{array}{l}{ }^{206} \mathrm{~Pb} / \\
{ }^{238} \mathrm{U}^{*}\end{array}$ & $\begin{array}{l}\text { error } \\
\%\end{array}$ & $\begin{array}{l}\text { error } \\
\text { correl }\end{array}$ & $\begin{array}{l}(\%) \\
\text { discor. \# }\end{array}$ & $\begin{array}{l}{ }^{207} \mathrm{~Pb} / 206 \mathrm{~Pb} \\
\mathrm{Edad}(\mathrm{Ma})\end{array}$ & $\begin{array}{l}\text { error } \\
(\mathrm{Ma})\end{array}$ \\
\hline PIN_22_32 & borde, herencia & $0.1104 \pm$ & 0.4 & $4.59 \pm$ & 1.4 & $0.3015 \pm$ & 1.4 & 0.962 & 3 & $1805.0 \pm$ & 7.1 \\
\hline PIN_22_46 & borde, herencia, $>4 \%$ discord. & $0.1104 \pm$ & 0.4 & $4.36 \pm$ & 1.3 & $0.2862 \pm$ & 1.2 & 0.959 & 5 & $1806.5 \pm$ & 6.5 \\
\hline PIN_22_39 & borde, herencia, $>4 \%$ discord. & $0.1105 \pm$ & 0.3 & $4.49 \pm$ & 1.4 & $0.2948 \pm$ & 1.4 & 0.972 & 4 & $1808.0 \pm$ & 6.1 \\
\hline PIN_22_23 & núcleo, alto ${ }^{204} \mathrm{~Pb},>4 \%$ discord. & $0.1124 \pm$ & 0.8 & $6.02 \pm$ & 3.7 & $0.3886 \pm$ & 3.6 & 0.977 & -7 & $1838.0 \pm$ & 14.4 \\
\hline PIN_22_48 & borde, herencia, $>4 \%$ discord. & $0.1129 \pm$ & 0.3 & $4.51 \pm$ & 1.6 & $0.2894 \pm$ & 1.6 & 0.981 & 5 & $1847.0 \pm$ & 5.6 \\
\hline PIN_22_6 & borde, alto ${ }^{204} \mathrm{~Pb},>4 \%$ discord. & $0.1133 \pm$ & 0.4 & $4.55 \pm$ & 1.7 & $0.2916 \pm$ & 1.6 & 0.977 & 5 & $1852.0 \pm$ & 6.5 \\
\hline \multicolumn{6}{|c|}{$\begin{array}{l}\text { Coordenadas geográficas: } 31^{\circ} 26^{\prime} 28^{\prime \prime}-113^{\circ} 16^{\prime} 42^{\prime \prime} \\
\text { (DATUM WGS-84) }\end{array}$} & \multicolumn{6}{|c|}{$\begin{array}{l}\text { Edad }{ }^{207} \mathbf{P b} /{ }^{206} \mathbf{P b} \text { media ponderada }=\mathbf{1 7 6 4} \pm \mathbf{3} \\
\operatorname{MSWD}=1.3, \mathrm{n}=29\end{array}$} \\
\hline$\frac{\text { Mues t } r \text { a }}{\underline{P I N-07-25}}$ & $\underline{\text { Gneis bandeado }}$ & \multicolumn{4}{|c|}{ (Zona Canteras-Puerto Peñasco) } & \multicolumn{6}{|c|}{ Probeta HARIM-1 (Abril 08) } \\
\hline PIN_25_28 & núcleo, pérdida de $\mathrm{Pb}$ & $0.0895 \pm$ & 0.1 & $2.77 \pm$ & 3.3 & $0.2244 \pm$ & 3.3 & 0.999 & 3 & $1415.0 \pm$ & 2.3 \\
\hline PIN_25_29 & borde, pérdida de $\mathrm{Pb}$ & $0.0998 \pm$ & 0.2 & $3.74 \pm$ & 3.4 & $0.2716 \pm$ & 3.4 & 0.998 & 2 & $1621.0 \pm$ & 3.7 \\
\hline PIN_25_35 & borde, pérdida de $\mathrm{Pb}$ & $0.1019 \pm$ & 0.4 & $3.95 \pm$ & 3.2 & $0.2814 \pm$ & 3.2 & 0.991 & 2 & $1659.0 \pm$ & 7.9 \\
\hline PIN_25_24 & borde, pérdida de $\mathrm{Pb}$ & $0.1025 \pm$ & 0.4 & $4.02 \pm$ & 3.5 & $0.2843 \pm$ & 3.5 & 0.994 & 1 & $1669.0 \pm$ & 7.0 \\
\hline PIN_25_18 & borde, pérdida de $\mathrm{Pb}$ & $0.1027 \pm$ & 0.3 & $3.85 \pm$ & 2.7 & $0.2715 \pm$ & 2.7 & 0.994 & 3 & $1673.5 \pm$ & 5.5 \\
\hline PIN_25_7 & núcleo, pérdida de $\mathrm{Pb}$ & $0.1028 \pm$ & 0.3 & $3.73 \pm$ & 5.0 & $0.2632 \pm$ & 5.0 & 0.998 & 4 & $1674.5 \pm$ & 6.1 \\
\hline PIN_25_25 & núcleo, pérdida de $\mathrm{Pb}$ & $0.1034 \pm$ & 0.1 & $3.97 \pm$ & 3.2 & $0.2782 \pm$ & 3.2 & 0.999 & 3 & $1686.5 \pm$ & 2.4 \\
\hline PIN_25_43 & núcleo, pérdida de $\mathrm{Pb}$ & $0.1037 \pm$ & 0.1 & $4.09 \pm$ & 3.6 & $0.2863 \pm$ & 3.6 & 1.000 & 2 & $1691.0 \pm$ & 1.9 \\
\hline PIN_25_47 & núcleo, pérdida de $\mathrm{Pb}$ & $0.1039 \pm$ & 0.1 & $4.10 \pm$ & 3.3 & $0.2863 \pm$ & 3.3 & 0.999 & 2 & $1694.5 \pm$ & 2.2 \\
\hline PIN_25_9 & borde, $>4 \%$ discord. & $0.1041 \pm$ & 0.3 & $3.38 \pm$ & 5.0 & $0.2353 \pm$ & 5.0 & 0.998 & 9 & $1698.0 \pm$ & 5.9 \\
\hline PIN_25_48 & borde, pérdida de $\mathrm{Pb}$ & $0.1043 \pm$ & 0.2 & $4.17 \pm$ & 3.5 & $0.2899 \pm$ & 3.5 & 0.999 & 2 & $1702.0 \pm$ & 3.3 \\
\hline PIN_25_11 & núcleo, pérdida de $\mathrm{Pb}$ & $0.1044 \pm$ & 0.3 & $4.48 \pm$ & 3.3 & $0.3111 \pm$ & 3.3 & 0.996 & -1 & $1702.5 \pm$ & 5.2 \\
\hline PIN_25_23 & borde, pérdida de $\mathrm{Pb}$ & $0.1043 \pm$ & 0.2 & $4.13 \pm$ & 3.7 & $0.2871 \pm$ & 3.7 & 0.998 & 2 & $1702.5 \pm$ & 4.5 \\
\hline PIN_25_41 & núcleo, pérdida de $\mathrm{Pb}$ & $0.1044 \pm$ & 0.1 & $4.00 \pm$ & 3.4 & $0.2779 \pm$ & 3.4 & 1.000 & 3 & $1704.0 \pm$ & 1.9 \\
\hline PIN_25_33 & borde, pérdida de $\mathrm{Pb}$ & $0.1046 \pm$ & 0.1 & $4.04 \pm$ & 3.6 & $0.2800 \pm$ & 3.6 & 1.000 & 3 & $1707.0 \pm$ & 1.5 \\
\hline PIN_25_34 & borde, pérdida de $\mathrm{Pb}$ & $0.1048 \pm$ & 0.2 & $4.22 \pm$ & 3.5 & $0.2916 \pm$ & 3.5 & 0.998 & 2 & $1711.5 \pm$ & 3.5 \\
\hline PIN_25_14 & núcleo, mal análisis & $\theta .1049 \pm$ & 2.8 & $4.36 \pm$ & 11.8 & $0.3013 \pm$ & 11.5 & 0.972 & 0 & $1713.0 \pm$ & 50.7 \\
\hline PIN_25_49 & núcleo, pérdida de $\mathrm{Pb}$ & $0.1049 \pm$ & 0.1 & $4.24 \pm$ & 3.6 & $0.2928 \pm$ & 3.6 & 0.999 & 1 & $1713.0 \pm$ & 2.6 \\
\hline PIN_25_17 & núcleo & $0.1051 \pm$ & 0.3 & $4.19 \pm$ & 2.9 & $0.2891 \pm$ & 2.9 & 0.993 & 2 & $1716.5 \pm$ & 6.1 \\
\hline PIN_25_12 & borde & $0.1052 \pm$ & 0.2 & $4.24 \pm$ & 2.7 & $0.2921 \pm$ & 2.7 & 0.996 & 2 & $1717.5 \pm$ & 4.2 \\
\hline PIN_25_38 & núcleo & $0.1053 \pm$ & 0.2 & $4.24 \pm$ & 3.4 & $0.2919 \pm$ & 3.4 & 0.998 & 2 & $1719.0 \pm$ & 3.7 \\
\hline PIN_25_26 & núcleo & $0.1053 \pm$ & 0.3 & $4.31 \pm$ & 3.7 & $0.2964 \pm$ & 3.7 & 0.997 & 1 & $1720.0 \pm$ & 5.2 \\
\hline PIN_25_42 & núcleo & $0.1053 \pm$ & 0.2 & $4.25 \pm$ & 3.4 & $0.2930 \pm$ & 3.4 & 0.999 & 2 & $1720.0 \pm$ & 3.1 \\
\hline PIN_25_30 & núcleo & $0.1056 \pm$ & 0.1 & $4.31 \pm$ & 3.4 & $0.2956 \pm$ & 3.4 & 0.999 & 1 & $1725.0 \pm$ & 2.7 \\
\hline PIN_25_32 & borde & $0.1057 \pm$ & 0.1 & $4.37 \pm$ & 3.6 & $0.2999 \pm$ & 3.6 & 0.999 & 1 & $1726.5 \pm$ & 2.7 \\
\hline PIN_25_6 & borde & $0.1057 \pm$ & 0.3 & $4.07 \pm$ & 5.0 & $0.2791 \pm$ & 5.0 & 0.998 & 4 & $1727.0 \pm$ & 5.7 \\
\hline PIN_25_1 & borde & $0.1058 \pm$ & 0.3 & $4.25 \pm$ & 5.3 & $0.2916 \pm$ & 5.3 & 0.998 & 2 & $1727.5 \pm$ & 5.7 \\
\hline PIN_25_46 & núcleo & $0.1058 \pm$ & 0.3 & $4.15 \pm$ & 3.3 & $0.2842 \pm$ & 3.3 & 0.996 & 3 & $1728.0 \pm$ & 5.2 \\
\hline PIN_25_8 & borde & $0.1059 \pm$ & 0.3 & $4.16 \pm$ & 5.1 & $0.2849 \pm$ & 5.1 & 0.998 & 3 & $1729.5 \pm$ & 5.7 \\
\hline PIN_25_21 & núcleo & $0.1061 \pm$ & 0.2 & $4.34 \pm$ & 3.4 & $0.2970 \pm$ & 3.4 & 0.999 & 1 & $1733.0 \pm$ & 3.1 \\
\hline PIN_25_2 & núcleo, herencia & $0.1062 \pm$ & 0.3 & $4.28 \pm$ & 5.3 & $0.2924 \pm$ & 5.3 & 0.998 & 2 & $1734.5 \pm$ & 5.6 \\
\hline PIN_25_44 & núcleo, herencia & $0.1065 \pm$ & 0.1 & $4.46 \pm$ & 3.9 & $0.3035 \pm$ & 3.9 & 0.999 & 1 & $1739.5 \pm$ & 2.7 \\
\hline PIN_25_27 & borde, herencia & $0.1065 \pm$ & 0.1 & $4.49 \pm$ & 3.7 & $0.3056 \pm$ & 3.7 & 0.999 & 0 & $1740.5 \pm$ & 2.7 \\
\hline PIN_25_39 & núcleo, herencia & $0.1065 \pm$ & 0.1 & $4.35 \pm$ & 3.6 & $0.2961 \pm$ & 3.6 & 1.000 & 2 & $1741.0 \pm$ & 1.9 \\
\hline PIN_25_15 & núcleo, herencia & $0.1066 \pm$ & 0.3 & $4.32 \pm$ & 3.1 & $0.2940 \pm$ & 3.1 & 0.996 & 2 & $1742.0 \pm$ & 4.8 \\
\hline PIN_25_37 & borde, herencia & $0.1067 \pm$ & 0.2 & $4.47 \pm$ & 3.6 & $0.3037 \pm$ & 3.6 & 0.999 & 1 & $1743.0 \pm$ & 2.9 \\
\hline
\end{tabular}


Tabla 3. Datos analíticos U-Pb por LA-MC-ICPMS de zircones de rocas paleoproterozoicas de la Zona Canteras-Puerto Peñasco, NW Sonora, México. (Cont.)

\begin{tabular}{|c|c|c|c|c|c|c|c|c|c|c|c|}
\hline $\begin{array}{l}\text { Número de } \\
\text { Punto }\end{array}$ & Comentarios & $\begin{array}{l}{ }^{207} \mathrm{~Pb} / \\
{ }^{206} \mathrm{~Pb}^{*}\end{array}$ & $\begin{array}{l}\text { error } \\
(\%)\end{array}$ & $\begin{array}{l}{ }^{207} \mathrm{~Pb} / \\
{ }^{235} \mathrm{U}^{*}\end{array}$ & $\begin{array}{l}\text { error } \\
(\%)\end{array}$ & $\begin{array}{l}{ }^{206} \mathrm{~Pb} / \\
{ }^{238} \mathrm{U}^{*}\end{array}$ & $\begin{array}{l}\text { error } \\
\%\end{array}$ & $\begin{array}{l}\text { error } \\
\text { correl }\end{array}$ & $\begin{array}{l}(\%) \\
\text { discor. } \#\end{array}$ & $\begin{array}{l}{ }^{207} \mathrm{~Pb} /{ }^{206} \mathrm{~Pb} \\
\mathrm{Edad}(\mathrm{Ma})\end{array}$ & $\begin{array}{l}\text { error } \\
(\mathrm{Ma})\end{array}$ \\
\hline PIN_25_40 & borde, herencia & $0.1067 \pm$ & 0.2 & $4.33 \pm$ & 3.6 & $0.2941 \pm$ & 3.6 & 0.999 & 2 & $1743.0 \pm$ & 2.9 \\
\hline PIN_25_22 & borde, herencia & $0.1068 \pm$ & 0.2 & $4.29 \pm$ & 3.4 & $0.2914 \pm$ & 3.4 & 0.999 & 2 & $1745.0 \pm$ & 2.9 \\
\hline PIN_25_3 & borde, herencia & $0.1069 \pm$ & 0.3 & $4.45 \pm$ & 5.5 & $0.3023 \pm$ & 5.5 & 0.998 & 1 & $1746.5 \pm$ & 5.7 \\
\hline PIN_25_50 & borde, herencia & $0.1069 \pm$ & 0.1 & $4.50 \pm$ & 3.6 & $0.3054 \pm$ & 3.6 & 0.999 & 1 & $1747.5 \pm$ & 2.1 \\
\hline PIN_25_10 & núcleo, herencia & $0.1070 \pm$ & 0.3 & $4.14 \pm$ & 5.1 & $0.2810 \pm$ & 5.1 & 0.998 & 4 & $1748.0 \pm$ & 5.9 \\
\hline PIN_25_19 & borde, herencia & $0.1073 \pm$ & 0.2 & $4.19 \pm$ & 2.9 & $0.2832 \pm$ & 2.9 & 0.997 & 4 & $1753.5 \pm$ & 4.2 \\
\hline PIN_25_4 & núcleo, herencia, $>4 \%$ discord. & $0.1074 \pm$ & 0.4 & $4.08 \pm$ & 5.2 & $0.2753 \pm$ & 5.2 & 0.997 & 5 & $1754.5 \pm$ & 6.8 \\
\hline PIN_25_31 & borde, herencia & $0.1073 \pm$ & 0.2 & $4.30 \pm$ & 3.4 & $0.2902 \pm$ & 3.4 & 0.999 & 3 & $1754.5 \pm$ & 2.9 \\
\hline PIN_25_5 & núcleo, herencia & $0.1075 \pm$ & 0.4 & $4.27 \pm$ & 5.0 & $0.2881 \pm$ & 5.0 & 0.997 & 3 & $1756.5 \pm$ & 6.5 \\
\hline PIN_25_45 & núcleo, herencia & $0.1075 \pm$ & 0.1 & $4.38 \pm$ & 3.4 & $0.2956 \pm$ & 3.4 & 1.000 & 2 & $1757.0 \pm$ & 1.8 \\
\hline PIN_25_36 & núcleo, herencia & $0.1075 \pm$ & 0.2 & $4.48 \pm$ & 3.5 & $0.3020 \pm$ & 3.5 & 0.999 & 1 & $1757.5 \pm$ & 2.9 \\
\hline PIN_25_16 & núcleo, herencia & $0.1076 \pm$ & 0.3 & $4.16 \pm$ & 2.6 & $0.2802 \pm$ & 2.6 & 0.992 & 4 & $1758.5 \pm$ & 5.9 \\
\hline PIN_25_20 & borde, herencia & $0.1077 \pm$ & 0.3 & $4.41 \pm$ & 2.9 & $0.2970 \pm$ & 2.8 & 0.995 & 2 & $1760.0 \pm$ & 5.5 \\
\hline PIN_25_13 & núcleo, herencia & $0.1082 \pm$ & 0.4 & $4.70 \pm$ & 3.4 & $0.3150 \pm$ & 3.4 & 0.995 & 0 & $1769.0 \pm$ & 6.4 \\
\hline \multicolumn{6}{|c|}{$\begin{array}{l}\text { Coordenadas geográficas: } 31^{\circ} 27^{\prime} 36^{\prime \prime}-113^{\circ} 17^{\prime} 52^{\prime \prime} \\
\text { (DATUM WGS-84) }\end{array}$} & \multicolumn{6}{|c|}{$\begin{array}{l}\mathbf{E d a d}{ }^{207} \mathbf{P b} /{ }^{206} \mathbf{P b} \text { media ponderada }=\mathbf{1 7 2 5} \pm \mathbf{3} \\
\operatorname{MSWD}=1.8, \mathrm{n}=12\end{array}$} \\
\hline
\end{tabular}

* Relaciones atómicas corregidas para los efectos del desvio instrumental (“drift”) usando el estándar de zircón FC-1. Todos los errores están reportados a nivel 1sigma con la excepción de la edad media ponderada reportada a 2 sigma.

\# Grados de discordancia definidos por la distancia porcentual que un análisis cae a lo largo de una línea de intersección de concordia generada por la extrapolación de las edades ${ }^{207} \mathrm{~Pb} /{ }^{206} \mathrm{~Pb}$ con el origen a $0 \mathrm{Ma}$. Valores positivos son para discordancia normal; valores negativos para discordancia inversa. Las edades en negrita fueron utilizadas para el cálculo de la edad ${ }^{207} \mathrm{~Pb} /{ }^{206} \mathrm{~Pb}$ media ponderada.

utilizando ${ }^{176} \mathrm{Lu} /{ }^{177} \mathrm{Hf}=0.015$ para una corteza intermedia promedio) en dos pasos entre 2.18-2.29 Ga (Tabla 8). Tres granos, con edades de cristalización de 1757, 1758 y $1759 \mathrm{Ma}$ (1-sigma), tienen una composición radiogénica épsilon $\mathrm{Hf}$ de $+4.24,+4.20$ y +4.06 , respectivamente, con sus correspondientes edades modelo $\mathrm{Hf}\left(\mathrm{T}_{\mathrm{DM}}\right)$ en un paso de 2.02 Ga para cada análisis y edades modelo $\mathrm{Hf}\left(\mathrm{T}_{\mathrm{DM} 2}{ }^{\mathrm{C}}\right)$ en dos pasos de 2.2 Ga para cada análisis (Tabla 8). Uno de los granos más viejos (Tabla 8; punto PIN-22-32; 1805 $\mathrm{Ma}$ ) tiene la composición inicial de Hf más radiogénica (épsilon Hf de +4.63) con su respectiva edad modelo en un paso de $2.04 \mathrm{Ga}$ y edad modelo $\left(\mathrm{T}_{\mathrm{DM} 2}{ }^{\mathrm{C}}\right)$ en dos pasos de $2.19 \mathrm{Ga}$. Una agrupación de cinco análisis con edades U-Pb entre 1711-1767 Ma (1-sigma) muestra valores de épsilon Hf entre +2.37 y +3.68 con sus correspondientes edades modelo $\mathrm{Hf}\left(\mathrm{T}_{\mathrm{DM}}\right)$ en un paso entre 2.05-2.06 Ga (y edades modelo Hf $\left(\mathrm{T}_{\mathrm{DM} 2}{ }^{\mathrm{C}}\right)$ entre 2.22-2.26 Ga. Tres análisis más con edades de 1733, 1753 y 1758 Ma proporcionan valores de épsilon $\mathrm{Hf}$ de $+2.57,+3.05$ y +3.23 con sus respectivas edades modelo $\mathrm{Hf}\left(\mathrm{T}_{\mathrm{DM}}\right)$ en un paso entre 2.05-2.07 Ga y edades modelo $\mathrm{Hf}\left(\mathrm{T}_{\mathrm{DM} 2}{ }^{\mathrm{C}}\right)$ entre 2.25-2.27 Ga. Por último, el zircón más viejo (1847 Ma; 1-sigma) tiene un valor de épsilon $\mathrm{Hf} \mathrm{de}+3.68$ y una edad modelo $\left(\mathrm{Hf}_{\mathrm{DM}}\right.$ ) en un paso de 2.12 Ga y una edad modelo $\mathrm{Hf}\left(\mathrm{T}_{\mathrm{DM} 2}{ }^{\mathrm{C}}\right)$ en dos pasos de $2.29 \mathrm{Ga}$. La Figura 8C muestra imágenes de catodoluminiscencia (CL) de los granos de zircón señalando el lugar del punto de ablación para los análisis geocronológicos $(\mathrm{U}-\mathrm{Pb})$ e isotópicos (Lu-Hf).

La segunda muestra de gneis bandeado cuarzo-feldespático de biotita-moscovita (PIN-07-25) tiene una edad ${ }^{207} \mathrm{~Pb} /{ }^{206} \mathrm{~Pb}$ de $1725 \pm 3 \mathrm{Ma}$ (2 sigma; Figura 4D; Tabla 3). Los doce análisis individuales de Lu-Hf realizados en zircones de esta muestra de gneis bandeado se presentan en la Tabla 8 y Figuras 8 y 9 . Estos doce datos isotópicos proporcionan un valor de épsilon $\mathrm{Hf}$ inicial medio ponderado de $3.0 \pm 0.57$ (MSWD =0.68: $\mathrm{n}=12$ ) como se muestra en el histograma de la Figura $8 \mathrm{D}$ y con sus respectivas edades modelo $\mathrm{Hf}\left(\mathrm{T}_{\mathrm{DM}}\right)$ en un paso entre 1.98-2.06 Ga mostradas en el histograma de la Figura $8 \mathrm{E}$ y edades modelo Hf $\left(\mathrm{T}_{\mathrm{DM} 2}{ }^{\mathrm{C}}\right)$ en dos pasos entre 2.13-2.28 Ga. Los dos zircones más jóvenes (Tabla 8; puntos PIN-25-25 y PIN-25-7; 1686 y $1675 \mathrm{Ma}$ ) tienen valores de épsilon $\mathrm{Hf}$ inicial de +1.85 y +2.21 y edades modelo $\mathrm{Hf}\left(\mathrm{T}_{\mathrm{DM}}\right)$ en un paso de 2.05 y 2.02 Ga y edades modelo $\mathrm{Hf}\left(\mathrm{T}_{\mathrm{DM} 2}{ }^{\mathrm{C}}\right)$ en dos pasos de 2.28 y 2.25 $\mathrm{Ga}$, respectivamente. Ocho análisis, con edades entre 1702$1730 \mathrm{Ma}$, arrojaron valores iniciales de épsilon $\mathrm{Hf}$ entre +2.33 y +3.49 con edades modelo en un paso entre 2.00-2.05 Ga. Los dos granos más viejos (1760 y $1747 \mathrm{Ma}$ ) presentan valores de épsilon $\mathrm{Hf}$ de $+5.05 \mathrm{y}+2.96$ cuyas edades modelo en un paso son de $1.98 \mathrm{Ga}$ y $2.06 \mathrm{Ga}$ y edades modelo $\mathrm{Hf}$ $\left(\mathrm{T}_{\mathrm{DM} 2}{ }^{\mathrm{C}}\right)$ en dos pasos de 2.13 y $2.25 \mathrm{Ga}$, respectivamente. La Figura 8F muestra imágenes de catodoluminiscencia de los zircones analizados por ablación láser para las determinaciones isotópicas de $\mathrm{Lu}-\mathrm{Hf}$ y $\mathrm{U}-\mathrm{Pb}$. 
Tabla 4. Elementos mayores y tierras raras de rocas paleoproterozoicas de la Zona Canteras-Puerto Peñasco, NW Sonora.

\begin{tabular}{|c|c|c|}
\hline & PIN-07-22 & PIN-07-25 \\
\hline $\mathrm{SiO}_{2}$ & 75.90 & 78.65 \\
\hline $\mathrm{TiO}_{2}$ & 0.18 & 0.13 \\
\hline $\mathrm{Al}_{2} \mathrm{O}_{3}$ & 11.56 & 11.68 \\
\hline $\mathrm{Fe}_{2} \mathrm{O}_{3}$ & 2.13 & 0.78 \\
\hline MnO & 0.01 & 0.01 \\
\hline MgO & 0.94 & 0.44 \\
\hline $\mathrm{CaO}$ & 0.40 & 2.15 \\
\hline $\mathrm{Na}_{2} \mathrm{O}$ & 1.93 & 4.03 \\
\hline $\mathbf{K}_{2} \mathbf{O}$ & 6.35 & 0.65 \\
\hline $\mathrm{P}_{2} \mathrm{O}_{5}$ & 0.04 & 0.04 \\
\hline PPI & 0.57 & 0.70 \\
\hline Total & 100.01 & 99.25 \\
\hline A/CNK* & 1.07 & 1.04 \\
\hline $\mathbf{A} / \mathbf{N K}_{\dagger}+$ & 1.15 & 1.59 \\
\hline La & 42.30 & 11.21 \\
\hline $\mathrm{Ce}$ & 80.02 & 20.55 \\
\hline Pr & 9.52 & 2.05 \\
\hline Nd & 33.91 & 7.01 \\
\hline Sm & 6.81 & 1.30 \\
\hline Eu & 2.24 & 1.20 \\
\hline Gd & 5.20 & 1.25 \\
\hline Tb & 0.61 & 0.19 \\
\hline Dy & 2.64 & 1.19 \\
\hline Но & 0.44 & 0.26 \\
\hline Er & 1.14 & 0.71 \\
\hline Yb & 1.12 & 0.74 \\
\hline Lu & 0.19 & 0.13 \\
\hline$\sum \mathbf{R E E}$ & 186.14 & 47.80 \\
\hline$(\mathbf{L a} / \mathbf{Y} \mathbf{b})_{\mathrm{N}}$ & 25.47 & 10.17 \\
\hline $\mathbf{E u} / \mathbf{E} \mathbf{u}^{*}$ & 1.15 & 2.87 \\
\hline
\end{tabular}

Elementos mayores reportados como porcentaje en peso.

$\mathrm{Fe}$ Total está como $\mathrm{Fe}_{2} \mathrm{O}_{3}$. PPI = Pérdida por ignición.

(*) $\mathrm{A} / \mathrm{CNK}=$ relación molecular $\mathrm{Al}_{2} \mathrm{O}_{3} /\left(\mathrm{CaO}+\mathrm{Na}_{2} \mathrm{O}+\mathrm{K}_{2} \mathrm{O}\right)$.

$(\dagger) \mathrm{A} / \mathrm{NK}=$ relación molecular $\mathrm{Al}_{2} \mathrm{O}_{3} /\left(\mathrm{Na}_{2} \mathrm{O}+\mathrm{K}_{2} \mathrm{O}\right)$.

Los valores usados para normalizar las REE de La, $\mathrm{Yb}, \mathrm{Eu}, \mathrm{Sm}$ y Gd para determinar los cocientes normalizados de $(\mathrm{La} / \mathrm{Yb}) \mathrm{N}$ y Eu/Eu* son valores condríticos de Boyton (1983).

En resumen, las dos rocas gnéisicas bandeadas paleoproterozoicas (1764 y $1725 \mathrm{Ma}$ ) de la Zona Canteras-Puerto Peñasco muestran valores de épsilon Hf inicial entre +1.85 $\mathrm{y}+5.05$ y presentan edades modelo de $\mathrm{Hf}\left(\mathrm{T}_{\mathrm{DM}}\right)$ en un paso relacionadas al manto empobrecido entre 1.98-2.12 Ga (Figura 9) y edades modelo $\mathrm{Hf}\left(\mathrm{T}_{\mathrm{DM} 2}{ }^{\mathrm{C}}\right)$ en dos pasos entre 2.13-2.29 Ga, sugiriendo la fusión de una fuente mantélica con aporte cortical de corteza pre-existente.
Tabla 5. Elementos traza de rocas paleoproterozoicas de la Zona CanterasPuerto Peñasco, NW Sonora.

\begin{tabular}{lrr}
\hline & PIN-07-22 & PIN-07-25 \\
\hline Li & 15.96 & 32.82 \\
Be & 1.66 & 9.04 \\
B & 15.22 & 46.03 \\
P & 152.81 & 170.27 \\
Sc & 2.05 & 1.01 \\
V & 3.37 & 10.93 \\
Cr & 2.34 & 8.49 \\
Co & 3.29 & 2.78 \\
Ni & 1.71 & 4.65 \\
Cu & 2.13 & 1.61 \\
Zn & 26.54 & 10.10 \\
Ga & 15.42 & 12.90 \\
Rb & 130.76 & 36.15 \\
Sr & 82.96 & 159.67 \\
Y & 11.80 & 6.77 \\
Zr & 283.68 & 156.32 \\
Nb & 12.62 & 3.19 \\
Sb & 0.07 & 0.08 \\
Cs & 147.55 & 54.57 \\
Ba & 0.78 & 3.22 \\
Hf & 1861.40 & 173.94 \\
Ta & 7.94 & 3.71 \\
W & 0.74 & 0.19 \\
Pl & 0.13 & 0.40 \\
Th & 0.43 & 0.18 \\
Ba/Nb & 9.92 & 5.47 \\
\hline & 16.04 & 1.14 \\
\hline
\end{tabular}

Elementos traza en ppm

\section{Discusión}

\subsection{Geocronología U-Pb en zircones}

Los resultados geocronológicos U-Pb en zircones, presentados en este estudio, sugieren que los dos gneises bandeados paleoproterozoicos de la Zona Canteras-Puerto Peñasco (Figuras 2A y 2B) tienen similitud con las rocas paleoproterozoicas reportadas en el área de Quitovac (Iriondo et al., 2004) y Cabeza Prieta-Pinacate (Nourse et al., 2005). Los zircones de ambas muestras están bien preservados y presentan una homogeneidad en composición y edad para cada una de ellas sugiriendo que estas rocas podrían ser ortogneises paleoproterozoicos como lo intuíamos por aspectos texturales de los mismos. Las nuevas edades $\mathrm{U}-\mathrm{Pb}$ en zircones (muestra PIN-07-22 $=1764 \pm 3$ Ma y muestra PIN-07-25 = $1725 \pm 3$ Ma; Figuras 4A y 4D; Tabla 3) no coinciden con las edades U-Pb paleoproterozoicas antes propuestas para la zona de estudio ( 1595-1709 Ma; Anderson 


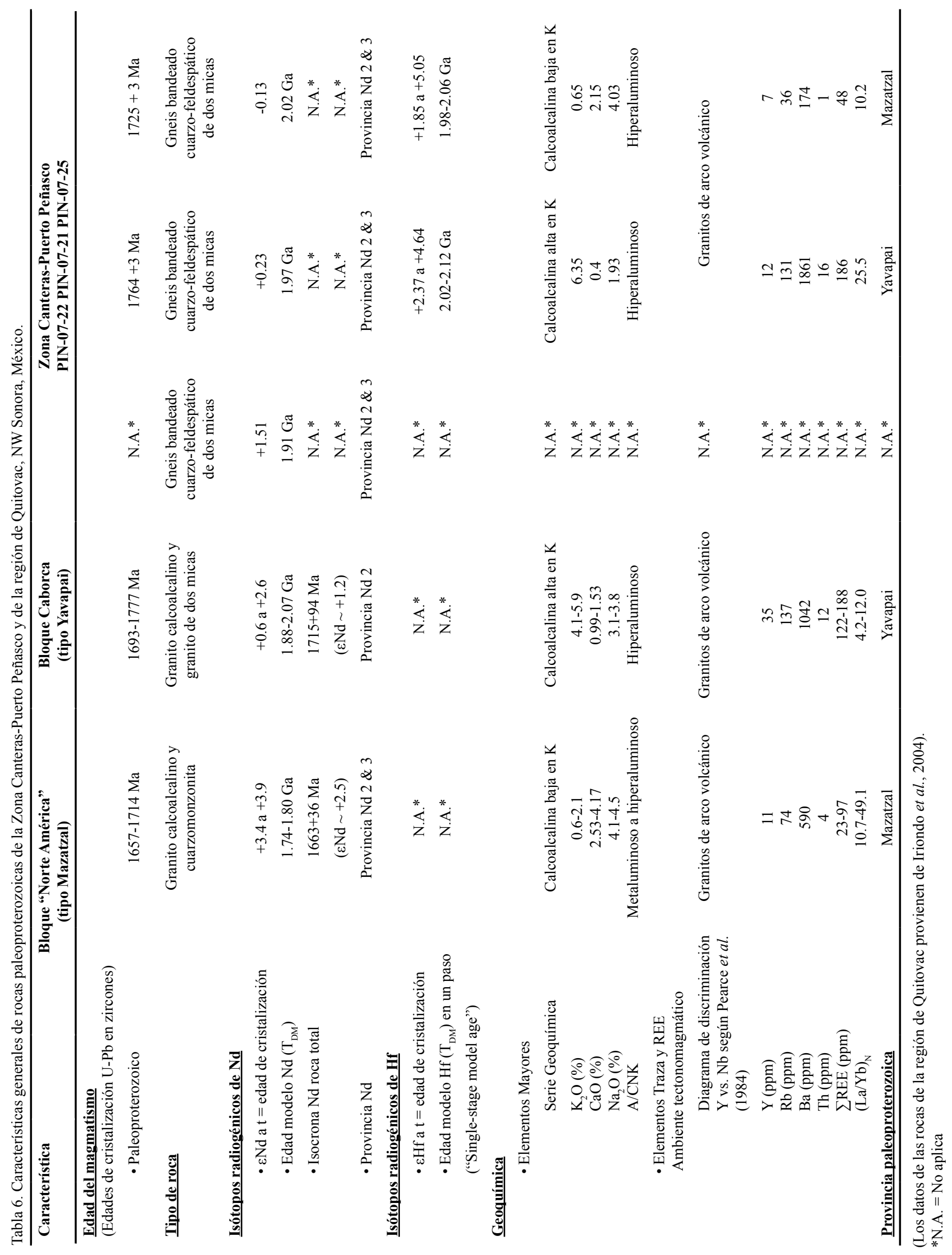


Tabla 7. Datos isotópicos Sm-Nd en roca total de rocas paleoproterozoicas de la Zona Canteras-Puerto Peñasco, NW Sonora, México.

\begin{tabular}{|c|c|c|c|c|c|c|c|c|c|c|c|}
\hline Muestra & Localización & $\begin{array}{l}\text { Tipo de } \\
\text { roca }\end{array}$ & $\begin{array}{l}\text { Edad } \\
(\mathrm{Ma})\end{array}$ & $\begin{array}{c}\mathrm{Sm}^{*} \\
(\mathrm{ppm})\end{array}$ & $\begin{array}{c}\mathrm{Nd}^{*} \\
(\mathrm{ppm})\end{array}$ & $\begin{array}{l}{ }^{147} \mathrm{Sm} / \\
{ }^{144} \mathrm{Nd}^{\dagger}\end{array}$ & $\begin{array}{l}{ }^{143} \mathrm{Nd} / \\
{ }^{144} \mathrm{Nd}^{\dagger}\end{array}$ & $\begin{array}{l}{ }^{143} \mathrm{Nd} / \\
{ }^{144} \mathrm{Ndi}{ }^{\S}\end{array}$ & $\mathrm{eNd}(0)^{\dagger}$ & eNd(i) $)^{\S}$ & $\begin{array}{l}\mathrm{T}_{\mathrm{DM}}{ }^{* *} \\
\text { (Ma) }\end{array}$ \\
\hline \multirow[t]{2}{*}{ PIN07-21 } & Zona Canteras & ortogneis & $\sim 1764$ & 1.9 & 8.9 & 0.1276 & 0.511929 & 0.510449 & -13.79 & 1.86 & 1907 \\
\hline & & & & & & 19 & 18 & & 35 & 35 & \\
\hline \multirow[t]{2}{*}{ PIN07-22 } & Zona Canteras & ortogneis & $1764 \pm 3$ & 6.3 & 34.0 & 0.1125 & 0.511692 & 0.510387 & -18.41 & 0.66 & 1972 \\
\hline & & & & & & 17 & 15 & & 35 & 35 & \\
\hline \multirow[t]{2}{*}{ PIN07-25 } & Zona Canteras & ortogneis & $1725 \pm 3$ & 1.2 & 6.9 & 0.1086 & 0.511607 & 0.510375 & -20.07 & -0.57 & 2018 \\
\hline & & & & & & 17 & 22 & & 43 & 43 & \\
\hline
\end{tabular}

(*) La reproducibilidad relativa (1-sigma) de las concentraciones de $\mathrm{Sm}$ y $\mathrm{Nd}$ es de $\pm 3.2 \% \mathrm{y} \pm 2.7 \%$, respectivamente.

$(\dagger)$ Todas las relaciones isotópicas de $\mathrm{Nd}$ se corrigieron por fraccionamiento de masas vía normalización a ${ }^{146} \mathrm{Nd} /{ }^{144} \mathrm{Nd}=0.7219$.

El valor medio de ${ }^{143} \mathrm{Nd} /{ }^{144} \mathrm{Nd}$ para 196 determinaciones del estandar La Jolla $\mathrm{Nd}$ en el LUGIS es de $0.511867 \pm 25$.

Los errores reportados a 1-sigma corresponden a los dos últimos dígitos de los valores analíticos.

(§) Los valores iniciales de ${ }^{143} \mathrm{Nd} /{ }^{144} \mathrm{Nd}$ y de eNd son calculados utilizando las edades de cristalización obtenidas por geocronología U-Pb en zircones; $\lambda=6.54 \times 10-12 / \mathrm{año} ;\left({ }^{143} \mathrm{Nd} /{ }^{144} \mathrm{Nd}\right)_{\text {CHUR }}=0.512638, \mathrm{y}\left({ }^{147} \mathrm{Sm} /{ }^{144} \mathrm{Nd}\right)_{\text {CHUR }}=0.1967$, donde CHUR $=$ chondritic uniform reservoir.

(**) Las edades modelo de $\mathrm{Nd}\left(\mathrm{T}_{\mathrm{DM}}\right)$ son calculadas con respecto al modelo de evolución del manto empobrecido (depleted mantle $\left.\mathrm{DM}\right)$ resolviendo $\mathrm{T}$ (edad en Ga) de la expresión: $\varepsilon N d\left({ }_{T}\right)=0.25 \mathrm{~T}^{2}-3 \mathrm{~T}+8.5($ DePaolo, 1981$)$.

Los parámetros usados para los cálculos son: $\lambda=1.865 \times 10^{-11} \mathrm{años}^{-1} ;{ }^{176} \mathrm{Lu} /{ }^{177} \mathrm{Hf}=0.0332 \mathrm{y}{ }^{176} \mathrm{Hf} /{ }^{177} \mathrm{Hf}=0.282772$ para el reservorio condrítico $(\mathrm{Bli}-$ chert-Toft y Albarede, 1997); ${ }^{176} \mathrm{Lu} /{ }^{177} \mathrm{Hf}=0.0384 \mathrm{y}{ }^{176} \mathrm{Hf} /{ }_{177} \mathrm{Hf}=0.28325$ para el manto empobrecido (Nowell et al., 1998; Griffin et al., 2000).

y Silver, 2005), ya que éstas estaban sustentadas por escasas determinaciones en poblaciones de zircones ( 2 análisis por muestra) utilizando la técnica convencional ID-TIMS (Isotope Dilution-Thermal Ionization Mass Spectrometry). La complejidad de los zircones paleoproterozoicos estudiados hasta la fecha en Sonora queda constatada por la presencia de efectos de herencias y pérdida de plomo. Esto último asociado a los diferentes eventos tectónicos que han experimentado estas rocas desde tiempos precámbricos, principalmente el evento laramídico que lleva asociados deformación, metamorfismo y magmatismo (Iriondo et al., 2005).

\subsection{Implicaciones Geoquímicas}

Geoquímicamente, ambas muestras paleoproterozoicas contienen altos porcentajes de sílice (75.90-78.65 wt. \%) probablemente debido a la alta recristalización-silicificación que experimentaron durante el proceso de gneisificación. Ambos gneises presentan diferencias notables entre sí, reflejadas en los contenidos de elementos mayores, traza y tierras raras.

Por ejemplo, con respecto a la concentración de elementos traza y tierras raras, se puede decir que la muestra PIN-07-22 tiene altos contenidos en algunos elementos traza como el $\mathrm{Rb}$, Ba y Th y una notable diferencia en la sumatoria de REE con respecto a la muestra PIN-07-25, cuyos contenidos en elementos traza y tierras raras son bajos y contrastan con los valores de la muestra PIN-07-22 (Tablas 4 y 5). En el diagrama de discriminación tectonomagmática $\mathrm{Y}$ vs. $\mathrm{Nb}$, ambas muestras caen en el campo de formación de granitos de arco volcánico de la misma manera que las muestras paleoproterozoicas de Quitovac (Figura 5C).
De forma general, la muestra PIN-07-22 presenta mayor afinidad geoquímica con las rocas tipo Yavapai presentes en la región de Quitovac, mientras que la muestra PIN-07-25 se asemeja más geoquímicamente a las rocas tipo Mazatzal para esa misma región (Tabla 6; Iriondo et al., 2004).

\subsection{Estudios isotópicos de $\mathrm{Sm}-\mathrm{Nd}$ en roca total y Lu-Hf en zircones}

Los datos isotópicos $\mathrm{Sm}-\mathrm{Nd}$ en roca total obtenidos para tres muestras de gneises bandeados paleoproterozoicos de la Zona Canteras-Puerto Peñasco presentan valores iniciales de épsilon $\mathrm{Nd}$ en un rango que va desde +1.86 hasta -0.57 con correspondientes edades modelo $\mathrm{Nd}\left(\mathrm{T}_{\mathrm{DM}}\right)$ de $1.91 \mathrm{a}$ $2.02 \mathrm{Ga}$ (Tabla 7). Estos valores indican que las fuentes de los magmas precursores de los gneises paleoproterozoicos pudieron derivar de la fusión parcial de una fuente mantélica con algún grado de contribución cortical, similar a las rocas de la provincia Yavapai en el SW de Norteamérica, incluyendo la región de Quitovac y algunas otras áreas con características similares en el NW de Sonora (Figura 2A; p.ej., Valenzuela-Navarro et al., 2003; Iriondo et al., 2004; Nourse et al., 2005; Amato et al., 2008; Gutiérrez-Coronado et al., 2008; Izaguirre et al., 2008).

En el gráfico de evolución de Nd (Figura 7) se muestran los rangos de edades $\mathrm{U}-\mathrm{Pb}$ en zircones y los valores iniciales de épsilon $\mathrm{Nd}$ de las muestras de gneises bandeados paleoproterozoicos y se grafican junto con datos publicados de rocas ígneas de las provincias de basamento paleoproterozoico del NW de Sonora. En este gráfico las muestras PIN-07-21 y PIN-07-22 caen claramente dentro de la Provincia Nd 2 (Yavapai, Bennett y DePaolo, 1987), mientras que la muestra PIN-07-25 cae en el campo de la provincia Nd 1 (Mojave), cerca del límite entre las 


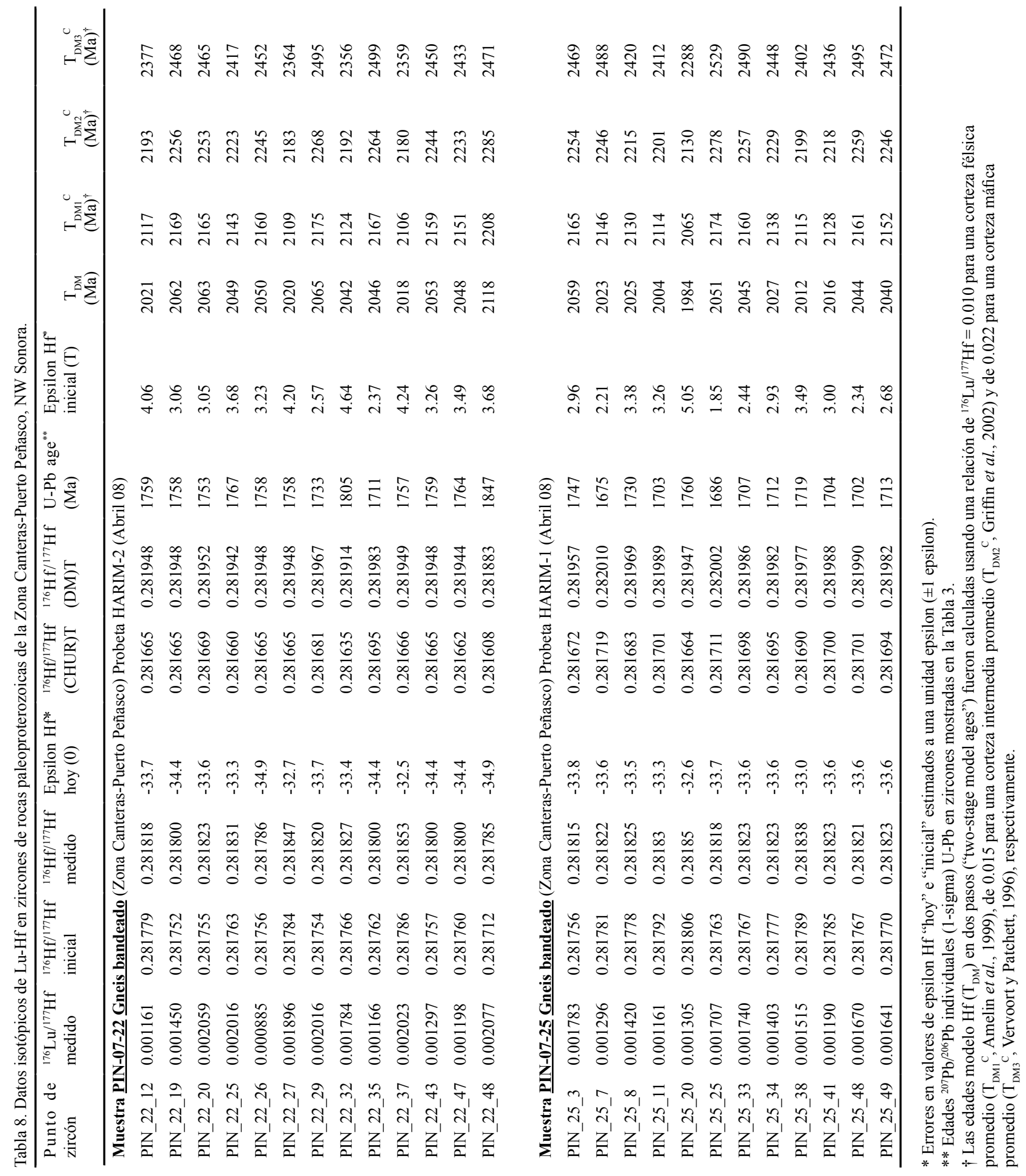


Provincias Nd 1 y 2 (Mojave-Yavapai), y pensamos que representa una roca Yavapai pero con mayor grado de contribución cortical que las otras dos muestras de gneis.

Por otro lado, conviene destacar que todas nuestras rocas contrastan claramente con los granitoides paleoproterozoicos de la provincia Mojave en la región de Death Valley que están caracterizados por valores iniciales de épsilon $\mathrm{Nd}$ entre -5.5 y -1.4 con correspondientes edades modelo $\mathrm{Nd}$ $\left(\mathrm{T}_{\mathrm{DM}}\right)$ entre 2.0 y $2.6 \mathrm{Ga}$ (Provincia Nd 1; Tabla 1 y Figura 7), representando una corteza altamente evolucionada con una componente cortical neoarqueana (Rämö y Calzia, 1998).

En general, concluimos que los gneises paleoproterozoicos de la Zona Canteras-Puerto Peñasco son similares en edad y firma isotópica de $\mathrm{Nd}$ a las rocas de la provincia Yavapai del SW de los EUA como las definidas en la región de Quitovac (Iriondo et al., 2004; Tabla 6), Cabeza Prieta-Pinacate (Nourse et al., 2005) y en otros lugares del NW de Sonora.

Los análisis de Lu-Hf en zircones, utilizados como trazador isotópico de nuestras rocas paleoproterozoicas, son los primeros estudios de este tipo realizados en rocas mexicanas. En la actualidad, no existen muchos datos Lu-Hf similares a los obtenidos para rocas de basamento paleoproterozoico del SW de Laurencia que sirvan como base de comparación para interpretar los datos analíticos generados en este estudio. Sólo los estudios de Bickford et al. (2008) muestran datos de Lu-Hf en zircones de rocas ígneas paleoproterozoicas de la provincia Yavapai en Colorado, EUA, en la región de Gunnison-Salida, en donde comparan estos datos de Lu-Hf en zircones con datos isotópicos de $\mathrm{Sm}-\mathrm{Nd}$ en roca total para rocas de la misma región (Hill, 2004), cuyas edades U-Pb de cristalización van desde 1700 hasta $1766 \mathrm{Ma}$ (Bickford et al., 1989; Hill y Bickford, 2001). Los valores de épsilon Hf inicial para estas rocas presentan intervalos principalmente entre +1.07 $\mathrm{y}+5.63 \mathrm{y}$ en ocasiones más altos, entre $+8.71 \mathrm{y}+14.79$, con edades modelo $\mathrm{Hf}\left(\mathrm{T}_{\mathrm{DM}}\right)$ en un paso entre 1.58 y $2.21 \mathrm{Ga}$ (Bickford et al., 2008).

En el presente estudio, en rocas de la Zona CanterasPuerto Peñasco, se han determinado valores iniciales de épsilon $\mathrm{Hf}$ entre $+1.85 \mathrm{y}+5.05$ y edades modelo de $\mathrm{Hf}$ $\left(\mathrm{T}_{\mathrm{DM}}\right)$ en un paso entre 1.98 y $2.12 \mathrm{Ga}$, respectivamente (Tabla 8, Figuras 8 y 9), comparables con los datos de $\mathrm{Sm}-\mathrm{Nd}$ en roca total para las mismas rocas que discutimos anteriormente. Estos datos Lu-Hf son similares a los obtenidos por Bickford et al. (2008) para rocas tipo Yavapai en Colorado y nos permiten corroborar la idea de que estas rocas presentan características tipo Yavapai sugiriendo que los magmas generadores de las mismas se derivan de fuentes mantélicas con algo de influencia de corteza continental preexistente (corteza inferior), algo similar a lo propuesto para zonas cercanas en Sonora como Quitovac, Cabeza Prieta-Pinacate, Cerro Prieto-Carina y Cerros San Luisito a partir de estudios de $\mathrm{Sm}-\mathrm{Nd}$ en roca total (Iriondo et al., 2004; Nourse et al., 2005; Gutiérrez-Coronado et al., 2008; Izaguirre et al., 2008).
Las edades modelo $\mathrm{Hf}\left(\mathrm{T}_{\mathrm{DM}}\right)$ en un paso ("single-stage model ages") calculadas en este estudio, utilizando la relación ${ }^{176} \mathrm{Lu} /{ }^{177} \mathrm{Hf}$ medida del zircón, proporcionan sólo una edad mínima para la fuente del magma a partir del cual cristalizó el zircón. Debido a esto se calculó, para cada zircón, una "edad modelo cortical" (edades modelo en dos pasos), la cual asume que la fuente del magma fue producida a partir de una corteza continental promedio (máfica, intermedia o félsica) que originalmente fue derivada del manto empobrecido. Las edades modelo $\mathrm{Hf}\left(\mathrm{T}_{\mathrm{DMC}}\right)$ en dos pasos ("two-stage model ages") fueron calculadas para la roca fuente del magma asumiendo valores de ${ }^{176} \mathrm{Lu} /{ }^{177} \mathrm{Hf}$ para diferentes cortezas modelo. Por ejemplo, se utilizaron relaciones de $176 \mathrm{Lu} / 177 \mathrm{Hf}=0.010$ para una corteza félsica promedio (Amelin et al., 1999), ${ }^{176} \mathrm{Lu} /{ }^{177} \mathrm{Hf}=0.015$ para una corteza intermedia promedio (Griffin et al., 2002) y ${ }^{176} \mathrm{Lu} /{ }^{177} \mathrm{Hf}=0.022$ para una corteza máfica promedio (Vervoort y Patchett, 1996; Tabla 8). Usar una relación Lu/Hf alta, típica de una corteza máfica promedio, como un reservorio huésped proporciona una edad modelo Hf máxima, mientras que los cálculos asumiendo un tipo de roca félsica proporciona edades modelo Hf mínimas. Por lo tanto, la edad modelo de Hf estimada para un zircón depende fuertemente de los parámetros de la fuente usados para el cálculo, es decir, la relación Lu/Hf que es usada para calcular la evolución isotópica de Hf del reservorio del zircón, desde el tiempo de la separación del manto empobrecido al tiempo de la formación del zircón.

En conclusión, los estudios isotópicos de $\mathrm{Sm}-\mathrm{Nd}$ y Lu-Hf indican que las rocas de la Zona Canteras-Puerto Peñasco están asociadas a rocas de la provincia Yavapai, y este hecho no parece apoyar la presencia de rocas tipo Mojave en esta zona, ya que las características petrogenéticas de estos gneises bandeados contrastan fuertemente con las características de las rocas tipo Mojave, en donde la participación de la corteza es significativamente mayor (Tabla 1). Esto implicaría que, de existir rocas tipo Mojave en el NW de Sonora, éstas deberían de encontrarse al oeste de la Zona Canteras Puerto-Peñasco.

\subsection{Distribución de provincias paleoproterozoicas en Sonora: Implicaciones tectónicas}

La ocurrencia de rocas paleoproterozoicas en la Zona Canteras-Puerto Peñasco en el NW de Sonora fortalece la idea actual sobre la distribución de las provincias de basamento paleoproterozoico en México (Figura 1) por corroborar la presencia de rocas tipo Yavapai en la parte más occidental del NW de Sonora. De esta manera, también se fortalece la hipótesis que propone la existencia de un doblez oroclinal hacia el SE, conocido como "doblez oroclinal Caborca" (Iriondo y Premo, 2009), que adquieren estas provincias paleoproterozoicas al adentrarse hacia México (Iriondo, 2007; Iriondo y Premo, 2009). Este doblez oroclinal quizás es resultado de la colisión de carácter oblicuo 

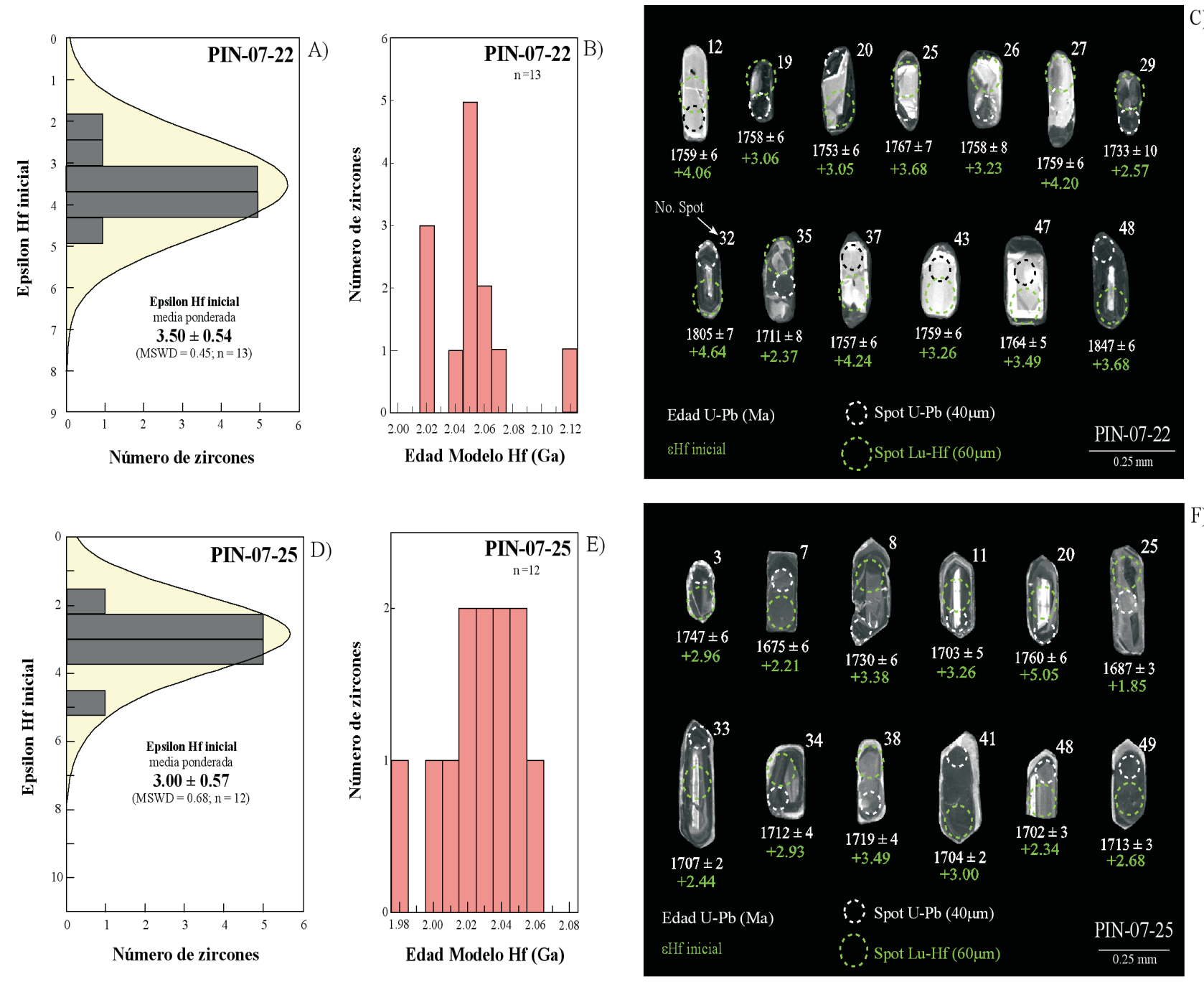

Figura 8. Datos de Hf en zircones e imágenes de catodoluminiscencia (CL) para rocas paleoproterozoicas de la Zona Canteras-Puerto Peñasco. (A) y (D) Diagramas de probabilidad que muestran el número de zircones analizados y los valores de épsilon Hf iniciales indicando una media ponderada de este valor para las muestras PIN-07-22 y PIN-07-25. (B) y (E) Histogramas graficando la edad modelo Hf $\mathrm{T}_{\mathrm{DM}}(\mathrm{Ga})$ individual en un paso ("single-stage model age") obtenida para cada análisis y el número de zircones analizados. (C) y (F) Imágenes de catodoluminiscencia (CL) mostrando los valores de épsilon Hf y la edad U-Pb de los zircones analizados. También se muestra el spot de ablación, lugar en donde se llevó a cabo cada análisis isotópico.

de arcos volcánicos paleoproterozoicos (Yavapai y Mazatzal) con corteza preexistente tipo Mojave y tiene una orientación geológica preferencial NW-SE en Sonora que contrasta con la orientación general NE-SW mostrada por las rocas paleoproterozoicas del SW de los EUA(Figura 1; Iriondo y Premo, 2009).

Estos avances en el conocimiento en la geología paleoproterozoica de Sonora permiten un mejor entendimiento del margen SW de Laurencia que podrá ser empleado para evaluar las diferentes reconstrucciones del supercontinente Rodinia propuestas hasta la fecha (Li et al., 2008).

A su vez, la ocurrencia de basamento tipo Yavapai encontrado en la Zona Canteras-Puerto Peñasco y en otros lugares del NW de Sonora también tiene implicaciones importantes en la evolución tectónica de la región, ya que se propone que este basamento Yavapai representa una zona de debilidad cortical (Iriondo, 2007; Iriondo y Premo, 2009) que pudo haber influido notablemente en diversos eventos geológicos importantes que han ocurrido desde tiempos proterozoicos hasta la actualidad a lo largo de esta franja del Yavapai mexicano. Por ejemplo, se piensa que esta zona de debilidad con orientación estructural NW-SE en Sonora (Figura 1), condicionó la orientación del rifting o ruptura del supercontinente Rodinia en el Neoproterozoico y el alineamiento de intrusivos asociados a un pulso magmático mesoproterozoico ( 1.1 Ga). Además, se cree que también pudo haber influido en otros eventos geológicos posteriores en Sonora, como la ubicación preferencial 


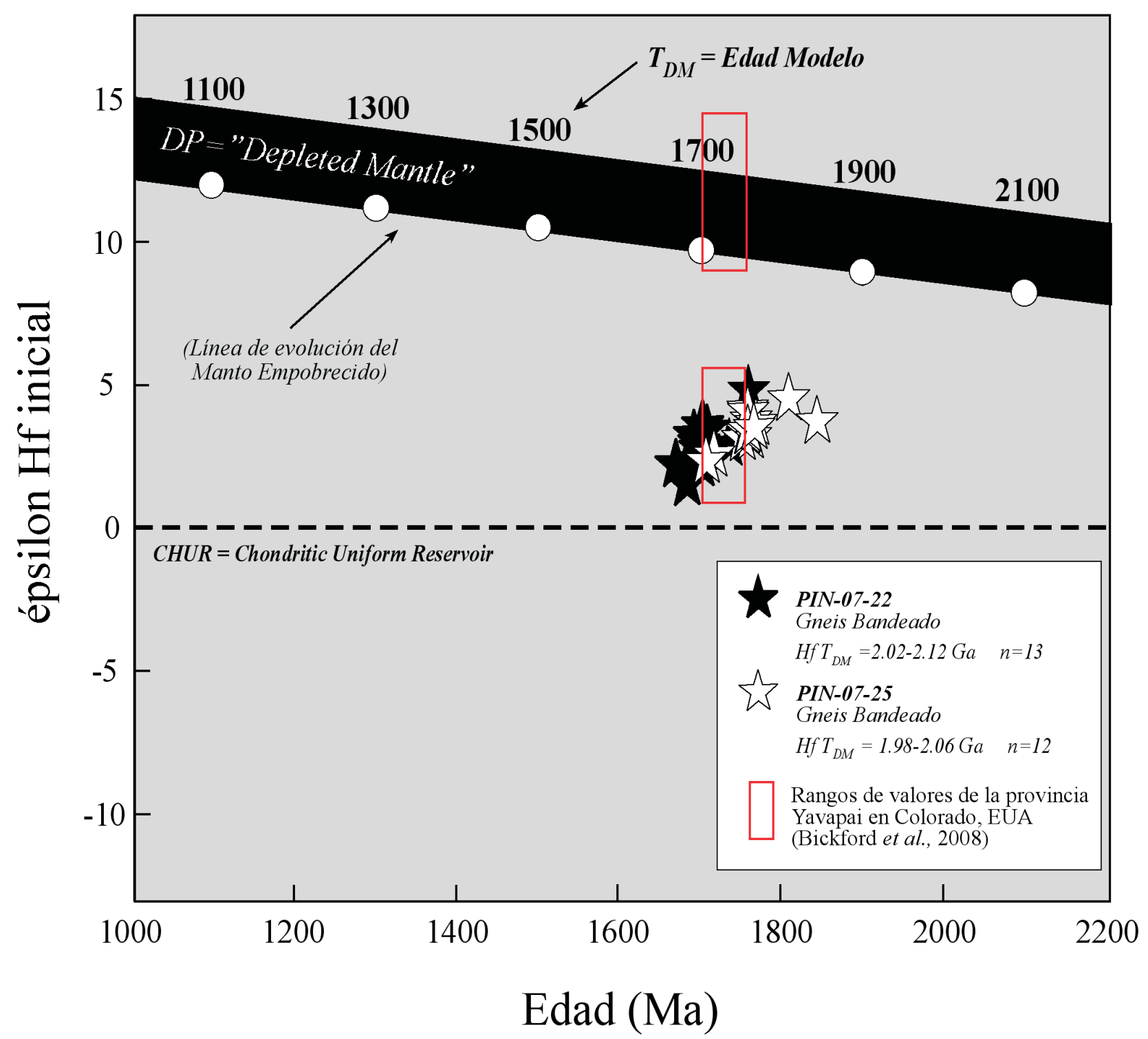

Figura 9. Diagrama de evolución del Hf para las rocas paleoproterozoicas de la Zona Canteras-Puerto Peñasco, NW de Sonora, en donde se grafica la edad $\mathrm{U}-\mathrm{Pb}(\mathrm{Ma})$ contra el valor de épsilon Hf inicial, mostrando además, el rango de valores de rocas graníticas paleoproterozoicas de la provincia Yavapai en Colorado, EUA (Bickford et al., 2008).

para el emplazamiento del magmatismo y la formación de cuencas sedimentarias mesozoicas y la canalización de fluidos metamórficos para la formación del cinturón de Au orogénico laramídico, entre otros (Iriondo y Premo, 2009).

De hecho, una de las implicaciones más interesantes de este concepto de zona de debilidad es el descubrimiento de un pulso magmático pérmico en la Sierra Pinta en el NW de Sonora (Figura $2 \mathrm{~A}$ ) con edades U-Pb en zircones entre 275-258 Ma. Pensamos que esta zona de debilidad pudo haber servido para que los primeros magmas generados por subducción en el arco magmático continental (margen activo) pérmico del SW de Norteamérica (Arvizu-Gutiérrez,
2008; Arvizu et al., en preparación.) ascendieran hacia la superficie con mayor facilidad en su difícil camino a través de una corteza relativamente fría después de cientos de millones de años como corteza de margen continental pasivo formada posteriormente al rifting o ruptura del supercontinente Rodinia en el Neoproterozoico y/o Paleozoico Inferior.

Cabe señalar claramente que lo que consideramos zona de debilidad cortical Yavapai, es sólo una hipótesis para explicar algunos eventos geológicos ocurridos durante la evolución tectónica de Sonora cuya ocurrencia se encuentra espacialmente restringida a esta franja del Yavapai mexicano. 


\section{Conclusiones}

Con base en la caracterización temporal, geoquímica e isotópica realizada, se concluye que las rocas presentes en la Zona Canteras-Puerto Peñasco, representadas por gneises cuarzo-feldespáticos bandeados paleoproterozoicos, se correlacionan con rocas de la provincia Yavapai del SW de Norteamérica, similares a las propuestas en las regiones de Quitovac y Cabeza Prieta-Pinacate y otras zonas del NW de Sonora, además de la región de Gunnison-Salida en Colorado, EUA. Dicha caracterización contrasta con la petrogénesis de las rocas típicas de la provincia Mojave, caracterizadas por una gran contaminación cortical, implicando que de existir rocas tipo Mojave en el NW de Sonora, éstas deberían de encontrarse al oeste de la Zona Canteras-Puerto Peñasco.

La ocurrencia de basamento Yavapai en la Zona Canteras-Puerto Peñasco y la distribución de ésta provincia paleoproterozoica en el NW de Sonora ha servido como una zona de debilidad cortical y ha tenido influencia en la facilitación del ascenso de los primeros magmas generados por subducción asociados al establecimiento del margen continental activo de Norteamérica durante el Pérmico.

\section{Agradecimientos}

Agradecemos a las instituciones que otorgaron a Iriondo los proyectos PAPIIT/UNAM (clave IN113906-3) y CONACYT (clave 52163) por el financiamiento proporcionado para realizar trabajo de campo y estudios de laboratorio. De igual manera se agradece a la MINERA PENMONT por su apoyo logístico para llevar a cabo el trabajo de campo. Muchas gracias a Ofelia Pérez Arvizu por su colaboración en la realización de los análisis de elementos traza en el Laboratorio Ultralimpio y Espectrometría de Masas en el Centro de Geociencias de la Universidad Nacional Autónoma de México (CGEO-UNAM). A Juan Tomás Vásquez Ramírez y a Manuel Albarrán Murillo (ambos del CGEO) por la preparación de láminas delgadas para la petrografía y por la gran ayuda proporcionada en el trabajo de molienda y pulverización de las muestras, respectivamente. Agradecemos enormemente a Dan Miggins y Heather Lowers del U.S. Geological Survey de Denver por su ayuda en la obtención de imágenes de SEM-Catodoluminiscencia. Igualmente agradecemos a Luigi Solari por el apoyo ofrecido para obtener imágenes de luz reflejada y transmitida para caracterizar los zircones. Agradecemos también a Francisco Abraham Paz Moreno por sus valiosos comentarios sobre la geoquímica y asesoría para el estudio petrográfico. Finalmente queremos agradecer a Paul A. Mueller por invitarnos a realizar los fechamientos $\mathrm{U}-\mathrm{Pb}$ en zircones y las determinaciones isotópicas de Lu-Hf en los laboratorios de la Universidad de Florida en Gainesville, EUA.

\section{Bibliografía}

Amato, J., Lawton, T., Leggett, W., Mauel, D., González-León, C., Heizler, M., Farmer, G.L., 2008, Caborcan proterozoic basement in The Rancho La Lamina Region, Sonora, Mexico: U-Pb ages, Nd isotopic composition, ${ }^{40} \mathrm{Ar} /{ }^{39} \mathrm{Ar}$ thermochronology, and clast provenance indicate pre-Early Jurassic arrival and Laramide exhumation: Geological Society of America Abstracts with Programs, 40, 48.

Amelin, Y., Lee, D.C., Halliday, A.N., Pidgeon, R.T., 1999, Nature of the Earth's earliest crust from hafnium isotopes in single detrital zircons: Nature, 399, 252-255.

Anderson, T.H., Schmidt, V.A., 1983, The evolution of Middle America and the Gulf of Mexico-Caribbean Sea region during Mesozoic time: Geological Society of America Bulletin, 94, 941-966.

Anderson, T.H., Silver, L.T., 1978, The nature and extent of Precambrian rocks in Sonora, Mexico [abs.], in Roldán-Quintana, J., Salas, G.A., (eds.), Resúmenes, Primer Simposio sobre la Geología y Potencial Minero en el Estado de Sonora: Hermosillo, Instituto de Geología, Universidad Nacional Autónoma de México, 9-10.

Anderson, T.H., Silver, L.T., 1979, The role of the Mojave-Sonora megashear in the tectonic evolution of northern Sonora, in Anderson, T.H., Roldán-Quintana, J., (eds.), Geology of northern Sonora: Geological Society of America Field Trip Guidebook, 7, 59-68.

Anderson, T.H., Silver, L.T., 2005, The Mojave-Sonora megashear-Field and analytical studies leading to the conception and evolution of the hypothesis, in Anderson, T.H., Nourse, J.A., McKee, J.W., Steiner, M.B., (eds.), The Mojave-Sonora megashear hypothesis: Development, assessment, and alternatives: Geological Society of America Special Paper 393, 1-50.

Anderson, J.L., Wooden, J.L., Bender, E.E., 1993, Mojave Province of southern California and vicinity, in Van Schmus, W.R., otros 24, (eds.), 1993: Transcontinental Proterozoic provinces, in Reed, J.C., Jr., Bickford, M.E., Houston, R.S., Link, P.K., Rankin, D.W., Sims, P.K., Van Schmus, W.R., (eds.), Precambrian: Conterminous U.S.: Geological Society of America, The Geology of North America C-2, 176-188.

Arvizu-Gutiérrez, H.E., 2008, El basamento paleoproterozoico YavapaiMazatzal en los alrededores de la Sierra Pinta, NW Sonora: Su importancia para el entendimiento del magmatismo pérmico y el inicio del margen continental activo de Norte América: Nuevo León, México, Universidad Autónoma de Nuevo León, Linares, Tesis de Licenciatura, $181 \mathrm{p}$.

Arvizu, H., Iriondo, A., Izaguirre, A., Chávez-Cabello, G., Kamenov, G.D., Solís-Pichardo, G., Foster, D.A., Lozano-Santa Cruz, R., 2009, Rocas graníticas pérmicas en la Sierra Pinta en el NW de Sonora, México: Magmatismo de subducción asociado al inicio del margen continental activo del SW de Norte América: Revista Mexicana de Ciencias Geológicas, 26(3), 709-728.

Bender, E.E., 1994, Petrology of Early Proterozoic granitoids from the southwestern United States: Implications for genesis and tectonics of the Mojave Crustal Province: Los Angeles, U.SA., University of Southern California, Los Angeles, Tesis Doctoral, $332 \mathrm{p}$.

Bennett, V.C., DePaolo, D.J., 1987, Proterozoic crustal history of the western United States as determined by neodymium isotopic mapping: Geological Society of America Bulletin, 99, 674-685.

Bickford, M.E., Shuster, R.D., Boardman, S.J., 1989, U-Pb geochronology of the Proterozoic volcano plutonic terrane in the Gunnison and Salida area, Colorado: in Grambling, J.A., Tewksbury, B.J., (eds.), Proterozoic geology of the southern Rocky Mountains: Geological Society of America Special Paper 235, 33-48.

Bickford, M.E., Mueller, P.A., Kamenov, G.D., Hill, B.M., 2008, Crustal evolution of southern Laurentia during the Paleoproterozoic: Insights from zircon $\mathrm{Hf}$ isotopic studies of ca. $1.75 \mathrm{Ga}$ rocks in central Colorado: Geology, 36, 555-558.

Black, L.P., Kamo, S.L., Williams, I.S., Mundil, R., Davis, D.W., Korsch, R.J., Foudoulis, C., 2003, The application of SHRIMP to Phanerozoic geochronology; a critical appraisal of four zircon standards: Chemical Geology, 200, 171-188. 
Black, L.P., Kamo, S.L., Allen, C.M., Davis, D.W., Aleinikoff, J.N., Valley, J.W., Mundil, R., Campbell, I.H., Korsch, R.J., Williams, I.S., Foudoulis, C., 2004, Improved 206 Pb/238U microprobe geochronology by the monitoring of trace-element-related matrix effect; SHRIMP, ID-TIMS, ELA-ICP-MS and oxygen isotope documentation for a series of zircon standards: Chemical Geology, 205, 115-140.

Blichert-Toft, J., Albarède, F., 1997, The Lu-Hf isotope geochemistry of chondrites and the evolution of the mantle-crust system: Earth and Planetary Science Letters, 148, 243-258.

Boyton, W.V., 1983, Cosmochemistry of the rare earth elements: Meteorite studies, in Henderson P., (ed.), Rare Earth Element Geochemistry: Amsterdam, Elsevier, 63-114.

Castiñeiras, P., Iriondo, A., Dórame-Navarro, M., Premo, W.R., Kunk, M.J., 2004a, Metamorphic evolution of the Bamuri Complex (Sonora, NW Mexico): New insights from field and petrographic data, en IV Reunión Nacional de Ciencias de la Tierra, Juriquilla, Querétaro, México, Libro de Resúmenes, 49.

Castiñeiras, P., Iriondo, A., Wooden, J.L., Dórame-Navarro, M., Premo, W.R., 2004b, Detrital zircón U-Pb SHRIMP geochronology of Proterozoic quartzites from the Bamuri Complex, NW Sonora, Mexico: Evidence for a Mojave connection, en IV Reunión Nacional de Ciencias de la Tierra, Juriquilla, Querétaro, México, Libro de Resúmenes, 215.

Castiñeiras, P., Budahn, J.R., Iriondo, A., Dórame-Navarro, M.A., 2005, Geochemical characteristics of proterozoic metasedimentary rocks from Bamuri and La Tortuga complexes, Mojave crustal province (NW Sonora, Mexico): Actas INAGEQ (Abstracts), 11, 110.

Cumming, G.L., Richards, J.R., 1975, Ore lead isotope ratios in a continuously changing earth: Earth and Planetary Science Letters, 28, 155-171.

Damon, P.E., Livingston, D.E., Giletti, B.J., 1961, Extension of the older Precambrian of the southwest into Sonora, Mexico: Geological Society of America Abstracts with Programs, 68, 158-159.

Damon, P.E., Livingston, D.E., Mauger, R.L., Giletti, B.J., Pantoja-Alor, J., 1962, Edad del Precámbrico "Anterior” y de otras rocas del Zócalo de la región de Caborca-Altar de la parte noroccidental del Estado de Sonora: Boletín del Instituto de Geología, Universidad Nacional Autónoma de México, 64, 11-44.

DePaolo, D.J., 1981, Neodymium isotopes in the Colorado Front Range and crust-mantle evolution in the Proterozoic: Nature, 291, 193-196.

Dórame-Navarro, M., Iriondo, A., Castiñeiras, P., Premo, W.R., 2004, Cartografía y geocronología del basamento Proterozoico metamórfico en los Cerros Tecolote, NW de Sonora, en IV Reunión Nacional de Ciencias de la Tierra, Juriquilla, Querétaro, México, Libro de Resúmenes, 59.

Dórame-Navarro, M., Iriondo, A., 2005, Cartografía, petrografía y geocronología de los Cerros Tecolote y su relación con el metamorfismo de los Cerros Bámuri y La Tortuga al sur de Caborca, NW de Sonora: GEOS, Unión Geofísica Mexicana, Resúmenes y Programa, 25, 85-86.

Farmer, G.L., Bowring, S.A., Matzel, J., Espinosa-Maldonado, G., Fedo, C., Wooden, J., 2005, Paleoproterozoic Mojave province in northwestern Mexico? Isotopic and U-Pb zircon geochronologic studies of Precambrian and Cambrian crystalline and sedimentary rocks, Caborca, Sonora, in Anderson, T.H., Nourse, J.A., McKee, J.W., Steiner, M.B., eds., The Mojave-Sonora megashear hypothesis: Development, assessment, and alternatives: Geological Society of America Special Paper 393, 183-198.

Griffin, W.L., Pearson, N.J., Belousova, E., Jackson, S.E., van Achterbergh, E., O'Reilly, S.Y., Shee, S.R., 2000, The Hf isotope composition of cratonic mantle: LAM-MC-ICPMS analysis of zircon megacrysts in kimberlites: Geochimica et Cosmochimica Acta, 64, 133-147.

Griffin, W.L., Wang, X., Jackson, S.E., Pearson, N.J., O'Reilly, S.Y., Xu, X., Zhou, X., 2002, Zircon chemistry and magma mixing, SE China: In-situ analysis of Hf isotopes, Tonglu and Pingtan igneous complexes: Lithos, 61, 237-269.

Gutiérrez-Coronado, A., Iriondo, A., Rodríguez-Castañeda, J.L., Wooden, J.L., Budahn, J.R., Lozano-Santa Cruz, R., Hernández-Treviño, T., 2008, Paleoproterozoic gneises of the San Luisito Hills in NW Sonora: Extending the Mexican Yavapai province of SW Laurentia: Geological Society of America Abstracts with Programs, 40, 144.
Hill, B.M., 2004, Paleoproterozoic of central Colorado: Island arcs or rifted older crust?:, Syracuse, New York, USA, Syracuse University, Ph.D. Thesis, $145 \mathrm{p}$.

Hill, B.M., Bickford, M.E., 2001, Paleoproterozoic rocks of central Colorado: Accreted arcs or extended older crust?: Geology, 29, 1015-1018.

Iriondo, A., 2007, Precambrian geology in NW Mexico: New ideas for the distribution of Paleoproterozoic crustal provinces in SW Laurentia: Symposium Ores \& Orogenesis: Circum-Pacific Tectonics, Geologic Evolution and Ore Deposits, Tucson, Arizona (Abstract 256), 94-95.

Iriondo, A., Premo, W.R., 2009, Las rocas cristalinas Proterozoicas de Sonora y su importancia para la reconstrucción del margen continental SW de Laurencia: La pieza mexicana del rompecabezas de Rodinia, en Calmus, T., (ed.), La geología de Sonora, Publicaciones Especiales, Instituto de Geología, Universidad Nacional Autónoma de México (en revisión).

Iriondo, A., Premo, W.R., Martínez-Torres, L.M., Budahn, J.R., Atkinson, W.W., Jr., Siems, D.F., Guarás-González, B., 2004, Isotopic, geochemical and temporal characterization of Proterozoic basement rocks in the Quitovac region, northwestern Sonora, Mexico: Implications for the reconstruction of the southwestern margin of Laurentia: Geological Society of America Bulletin, 116, 154-170.

Iriondo, A., Martínez-Torres, L.M., Kunk, M.J., Atkinson, W.W., Jr., Premo, W.R., McIntosh, W.C., 2005, Northward Laramide thrusting in the Quitovac region, northwestern Sonora, Mexico: Implications for the juxtaposition of Paleoproterozoic basement blocks and the MojaveSonora megashear hypothesis, in Anderson, T.H., Nourse, J.A., McKee, J.W., Steiner., M.B., (eds.), The Mojave-Sonora megashear hypothesis: Development, assessment, and alternatives: Geological Society of America Special Paper 393, 631-669.

Izaguirre-Pompa, A., Iriondo, A., 2007, Mesoproterozoic $(\sim 1.2 \mathrm{Ga})$ quartzite and intruding anorthosite $(\sim 1.08 \mathrm{Ga})$ from Sierra Prieta, NW Sonora: Mexican additions to the Precambrian history of SW Laurencia: Arizona Geological Society, Ores and Orogenesis Symposium, Abstracts with Programs, 147-148.

Izaguirre, A., Iriondo, A., Wooden, J.L., Budahn, J.R., Schaaf, P., 2008, Paleoproterozoic Orthogneisses from the Cerro Prieto Area: A new addition to the Mexican Yavapai province in NW Sonora: Geological Society of America Abstracts with Programs, 40, 143-144.

Li, Z.X., Bogdanova, S.V., Collins, A.S., Davison, A., De Waele, B., Ernst, R.E., Fitzsimons, I.C.W., Fuck, R.A., Gladkochub, D.P., Jacobs, J., Karlstrom, K.E., Lu, S., Natapov, L.M., Pease, V., Pisarevsky, S.A., Thrane, K., Vernikovsky, V., 2008, Assembly, configuration, and break-up history of Rodinia: A synthesis: Precambrian Research, 160, 179-210.

Lozano-Santa Cruz, R., Verma, S.P., Girón, P., Velasco, F., Morán, D., Viera, F., Chávez, G., 1995, Calibración preliminar de fluorescencia de rayos X para análisis cuantitativo de elementos mayores en rocas ígneas: Actas INAGEQ, 1, 203-208.

Ludwig, K.R., 2003, ISOPLOT Version 3.00, A geochronological toolkit for Microsoft Excel: Berkeley Geochronology Center Special Publication 4, $70 \mathrm{p}$.

Nakamura, N., 1974, Determination of REE, Ba, Fe, Mg, Na and K in carbonaceous and ordinary chondrites: Geochimica et Cosmochimica Acta, 38, 757-775.

Nourse, J.A., Premo, W.R., Iriondo, A., Stahl, E.R., 2005, Contrasting Proterozoic basement complexes near the truncated margin of Laurentia, northwestern Sonora-Arizona international border region, in Anderson, T.H., Nourse, J.A., McKee, J.W., Steiner, M.B., (eds.), The Mojave-Sonora megashear hypothesis: Development, assessment, and alternatives: Geological Society of America Special Paper 393, 123-182.

Nowell, G.M., Kempton, P.D., Noble, S.R., Fitton, J.G., Saunders, A.D., Mahoney, J.J., Taylor, R.N., 1998, High precision Hf isotope measurements of MORB and OIB by thermal ionisation mass spectrometry: insights into the depleted mantle: Chemical Geology, 149, 211-233.

Paces, J.B., Miller, J.D., 1993, Precise U-Pb ages for the Duluth Complex and related mafic intrusions, northeastern Minnesota: Geochrono- 
logical insights to physical, petrogenetic, paleomagnetic and tectonomagmatic processes associated with the $1.1 \mathrm{Ga}$ Midcontinent Rift system: Journal of Geophysical Research, 98, 13,997-14, 013.

Pearce, J.A., Harris, N.B.W., Tindle, A.G., 1984, Trace element discrimination diagrams for the tectonic interpretation of granitic rocks: Journal of Petrology, 25, 956-983.

Peccerillo, A., Taylor, S.R., 1976, Geochemistry of Eocene calc-alkaline volcanic rocks from The Kastamonu area, northern Turkey: Contributions of Mineralogy and Petrology, 58, 63-81.

Premo, W.R., Iriondo, A., Nourse, J.A., 2003, U-Pb zircon geochronology of Paleoproterozoic basement in northwestern Sonora, Mexico: Evidence for affinity to SW US provinces: Geological Society of America Cordilleran Section Abstracts with Programs, 35, 67.

Rämö, O.T., Calzia, J.P., 1998, Nd isotopic composition of cratonic rocks in the southern Death Valley region: Evidence for a substantial Archean source component in Mojavia: Geology, 26, 891-894.

Scherer, E., Munker, C., Mezger, K., 2001, Calibration of the lutetiumhafnium clock: Science, 293, 683-687.

Servicio Geológico Mexicano (SGM), 2002, Carta Geológico-Minera Puerto Peñasco H12-1, Sonora, escala 1:250,000.

Silver, L.T., Anderson, T.H., 1974, Possible left-lateral early to middle Mesozoic disruption of the southwestern North American Craton margin: Geological Society of America Abstracts with Programs, 6, 955.

Silver, L.T., Anderson, T.H., 1983, Further evidence and analysis of the role of the Mojave-Sonora megashear(s) in Mesozoic Cordilleran tectonics: Geological Society of America Abstracts with Programs, $15,273$.

Simonetti, A., Heaman, L.M., Hartlaub, R.P., Creaser, R.A., MacHattie, T.G., Bohm, C., 2005, U-Pb zircon dating by laser-ablation-MCICP-MS using a new multiple ion counting Faraday collector array: Journal of Applied Atomic Spectroscopy, 20, 677-686.
Soderlund, U., Patchett, P., Vervoort J., Isachsen, C., 2004, The 176Lu decay constant determined by $\mathrm{Lu}-\mathrm{Hf}$ and $\mathrm{U}-\mathrm{Pb}$ isotope systematics of Precambrian mafic intrusions: Earth and Planetary Science Letters, 219, 311-324.

Soto-Verdugo, L.C., 2006, El zócalo ígneo-metamórfico Sierrita Prieta, Sonora Norte Central, México: Características petrográficas, geoquímicas y geocronológicas: Tesis de Licenciatura, Universidad de Sonora, Hermosillo, Sonora, México, 113 p.

Sun, S.S., McDonough, W.F., 1989, Chemical and isotopic systematics of ocean basalts: Implications for mantle composition and processes, in Saunders A.D., Norry M.J., (eds.), Magmatism in ocean basins: Geological Society of London Special Publication, 42, 313-345.

Valenzuela-Navarro, L.C., Valencia-Moreno, M., Iriondo, A., Premo, W.R., 2003, The El Creston Granite: A new confirmed Paleoproterozoic locality in the Opodepe area, north-central Sonora, Mexico: Geological Society of America Abstracts with Programs, 32(4), 83.

Verma, S.P., Lozano-Santa Cruz, R., Girón P., Velasco F., 1996, Calibración preliminar de fluorescencia de rayos $\mathrm{X}$ para análisis cuantitativo de elementos traza en rocas ígneas: Actas INAGEQ, 2, 237-242.

Vervoort, J.D., Blichert-Toft, J., 1999, Evolution of the depleted mantle: $\mathrm{Hf}$ isotope evidence from juvenile rocks through time: Geochimica et Cosmochimica Acta, 63(3-4), 533-556.

Vervoort, J.D., Patchett, P.J., 1996, Behavior of hafnium and neodymium isotopes in the crust: Constraints from Precambrian crustally derived granites: Geochimica et Cosmochimica Acta, 60(19), 3,717-3,733.

Vervoort, J.D., Patchett, P.J., Söderlund, U., Baker, M., 2004, Isotopic composition of $\mathrm{Yb}$ and the determination of $\mathrm{Lu}$ concentrations and $\mathrm{Lu} / \mathrm{Hf}$ ratios by isotope dilution using MC-ICPMS: Geochemistry, Geophysics and Geosystems, 5, Q11002, doi:10.1029/2004GC000721.

Woodhead, J.D., Hergt J.M., 2005, A preliminary appraisal of seven natural zircon reference materials for in situ Hf isotope determination: Geostandards and Geoanalytical Research, 29, 183-195. 